\title{
Article \\ Integrative Study Assessing Space and Time Variations with Emphasis on Rare Earth Element (REE) Distribution and Their Potential on Ashes from Commercial (Colombian) Coal
}

\author{
Ana Cláudia Santos ${ }^{1, *(D)}$, Alexandra Guedes ${ }^{1}$ (D), David French ${ }^{2}$, Aurora Futuro ${ }^{3}$ and Bruno Valentim ${ }^{1}$ (D) \\ 1 Earth Science Institute-Porto Pole, Department of Geosciences, Environment and Spatial Plannings, \\ Faculty of Sciences, University of Porto, Rua do Campo Alegre s/n, 4169-007 Porto, Portugal; \\ aguedes@fc.up.pt (A.G.); bvvalent@fc.up.pt (B.V.) \\ 2 School of Biological, Earth and Environmental Sciences, University of New South Wales, \\ Sydney, NSW 2052, Australia; davidfrench474@gmail.com \\ 3 Centro de Recursos Naturais e Ambiente (CERENA), Faculty of Engineering, University of Porto, \\ Rua Dr. Roberto Frias s/n, 4200-465 Porto, Portugal; afuturo@fe.up.pt \\ * Correspondence: anasantos@fc.up.pt
}

Citation: Santos, A.C.; Guedes, A.; French, D.; Futuro, A.; Valentim, B. Integrative Study Assessing Space and Time Variations with Emphasis on Rare Earth Element (REE) Distribution and Their Potential on Ashes from Commercial (Colombian) Coal. Minerals 2022, 12, 194. https:// doi.org/10.3390/min12020194

Academic Editors: Eugeniusz Mokrzycki and Alicja

Uliasz-Bocheńczyk

Received: 21 December 2021

Accepted: 28 January 2022

Published: 2 February 2022

Publisher's Note: MDPI stays neutral with regard to jurisdictional claims in published maps and institutional affiliations.

Copyright: (c) 2022 by the authors. Licensee MDPI, Basel, Switzerland. This article is an open access article distributed under the terms and conditions of the Creative Commons Attribution (CC BY) license (https:/ / creativecommons.org/licenses/by/ $4.0 /)$.

\begin{abstract}
The increasing demand for rare earth elements (REEs), which is associated with their economic importance and the supply risk, has motivated the research for alternative secondary sources of these elements. Coal and coal combustion ash have been pointed out as promising REE raw materials. This research seeks to understand REE fractionation, from feed coals to ashes, considering seasonal variations, and to assess the trends within the ash fractions that can be used for further beneficiation processes. Colombian commercial feed coals, combustion ashes, and their respective fractions were sampled from a Portuguese power plant and were characterized via petrographical, mineralogical, and chemical analyses. The total REE concentrations in the feed coals studied range between 6.97 and 23.15 ppm, while, in the ashes, they vary from 159.9 to $266.6 \mathrm{ppm}$. Fly ash (FA) from electrostatic precipitator (ESP) presented higher concentrations than the bottom (BA) and economizer (ECO) ashes. Furthermore, REEs and the LREE/HREE ratio increased slightly towards the back rows of the ESP. In the feed coals, the REEs are significantly correlated with ash, and they occur in micrometric phosphate minerals intermixed with clays. In the ashes, the REEs were mostly detected in micrometric particles, with $\mathrm{P}$ and $\mathrm{Al}-\mathrm{Si}$ as the major components. The results from the fractioned samples show that the REEs were enriched in the fine $(<25 \mu \mathrm{m})$ and nonmagnetic fractions of the ESP FA. A single trial combining sieving and magnetic separation enabled the attainment of a REE recovery of $53 \%$, and a final enrichment factor of 1.25 . Coal combustion ashes and their respective size fractions are promising REE raw materials; however, the REE oxide concentrations are below the economical cutoff of $1000 \mathrm{ppm}$.
\end{abstract}

Keywords: fly ash; bottom ash; trace elements; partitioning; enrichment; recovery; XRF; XRD; petrography; ICP-MS

\section{Introduction}

The REEs [1] are considered strategic materials because they play a key role in vital segments of the economy, such as defense, green energies, electronics, and the chemical industries [2,3]. The natural deposits are unevenly distributed worldwide; China has almost $38 \%$ of the global reserves and has dominated production since the late 1980s [4]. Currently, the supply of REEs in Europe is dominated by China, at $98 \%$ [5], a total of $8 \%$ more than in 2006/2007 [6]. The growing demand rate (3.7-8.6\% per year) and their supply risk led to the classification of REEs as "critical" raw materials and has stimulated the search for alternative sources [6-11]. Coal, and especially coal combustion ashes, have been pointed out as promising sources of REEs, and many studies have been conducted concerning the REE contents, the modes of occurrence, and the extraction potential [11-30]. 
According to Ketris and Yudovich [31], the average REE content (lanthanide plus Y and Sc) in world hard coals is 72.1 ppm, approx. 2.5 times lower than in upper continental crust (UCC: 183.14 ppm; [32]). Nevertheless, several coal beds with concentrations above $0.1 \%$ have been identified and extensively studied (e.g., [33-36]). Little attention has been given to commercial thermal coals (usually highly beneficiated). According to the IEA, $76 \%$ of the coal traded in 2019 (1445 Mt) corresponded to thermal coal, and 10\% (approx. $110 \mathrm{Mt}$ ) was imported by Europe [37].

During coal combustion, the REEs tend to be retained on the solid residue, i.e., fly ash, bottom ash, and slag, because of their nonvolatile properties [38-40]. The average REE concentration in world coal combustion ashes was estimated by Fu et al. [41] as $435.45 \mathrm{ppm}$ (Sc not included), which is about 2.4 times higher than the concentration in UCC [32]. The distribution patterns of REEs from combustion ashes are comparable to the ashes obtained in the laboratory, which supports the nonpartitioning during combustion [17]. Nevertheless, it has been observed that REEs can be unevenly distributed among the combustion products and their respective fractions. Numerous studies have reported lower REE contents in bottom ashes relative to fly ashes [4,42-44]. Moreover, the LREE/HREE ratio tends to decrease towards the ESP back rows and with decreasing particle sizes, while the REE content increases [13,16,20-23,45-49]. The mechanisms behind these trends are not clear, but may include: (1) The vaporization-condensation of HREEs associated with the organic matter; and (2) The capture of the REE-bearing phase by glass of the variable grain size $([48])$.

Although the assessment of coal combustion ashes as REE raw material should consider several parameters (e.g., the extraction methods, the amount of material available, and the market prices), a preliminary assessment can be made on the basis of REE concentrations and their individual compositions ([18]).

On the basis of economic forecasts, the REEs were classified into "critical" (Nd, Eu, $\mathrm{Tb}, \mathrm{Dy}, \mathrm{Y}$, and Er), "uncritical" (La, Pr, Sm, and Gd), and "excessive" (Ce, Ho, Tm, Yb, and Lu) ([50]. The preliminary evaluation was made by plotting the percentage of critical REEs,

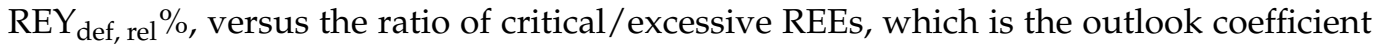
$\left(C_{\text {outl }}[18]\right)$. The method was recently updated by adding the cutoff of 1000 ppm REO, with REEs as oxides [51].

The utilization of coal combustion ashes as REE raw material offers some advantages over conventional ore exploration [10,18,22,52]: (1) Higher amounts of critical REEs; (2) No mining costs and, in the case of FA, milling is not necessary; (3) Lower concentrations of radionuclide; and (4) Reduction in/mitigation of environmental impacts. Even with decarbonization policies being implemented, and with several power plants being closed, the coal combustion products available, if not fresh, are landfilled. Just in $2016,36 \%$ of the coal combustion products produced worldwide (approx. $544 \mathrm{Mt}$ ) were not reutilized [53].

Several studies have been conducted to assess the coal combustion ash REE potential, but few have combined seasonal variations, sampling locations, and physical separations. The current research addresses the characterization of Colombian commercial feed coals and their respective combustion ashes, collected over one year from the Pego power plant (Portugal), with the main goals of understanding the REE distribution in the global samples, considering the space and time variations, and, in the physically separated fractions, by sieving and magnetic separation, as well as concomitantly assessing their REE potential.

\section{Materials and Methods}

\subsection{Samples}

The samples used in the present study were collected at the pulverized coal-fired thermoelectric power plant of Pego (Abrantes, Portugal), which operates at approx. $1500{ }^{\circ} \mathrm{C}$. The feed coals burned in Pego are commercial coals imported from Colombia.

The power plant is composed of two groups (Group 1 and Group 2), with a combined electrical power of $628 \mathrm{MW}$ (Figure 1). Each group is equipped with a pulverized coalfired boiler, a turbine alternator, a main transformer, and each has its own supporting 
infrastructure, including a cooling tower, a water supply, and an exhaust system. The boilers can burn up to $108 \mathrm{ton} / \mathrm{h}$ of pulverized coal, generating, at maximum, a continuous rating of more than 950 ton/h of superheated steam, at $535^{\circ} \mathrm{C}$ and 167 bar. The atmospheric emissions are minimized by selective catalytic reduction (SCR), electrostatic precipitators (ESPs), and wet flue gas desulphurization (FGD). The SCR system reduces $\mathrm{NO}_{\mathrm{x}}$ emissions by about $75 \%$ through a chemical reaction with ammonia $\left(\mathrm{NH}_{3}\right)$. Each group has two ESPs (arrays of 4 rows with 3 hoppers), with an efficiency per unit of $99.8 \%$. Few ash particles are collected upstream in the economizer (heat exchange device), only approximately $2 \%$, and they are forwarded to the same silo as the ESP ashes. The FGD system removes about $90 \%$ of the $\mathrm{SO}_{2}$ by a reaction with a slurry of limestone $\left(\mathrm{CaCO}_{3}\right)$.

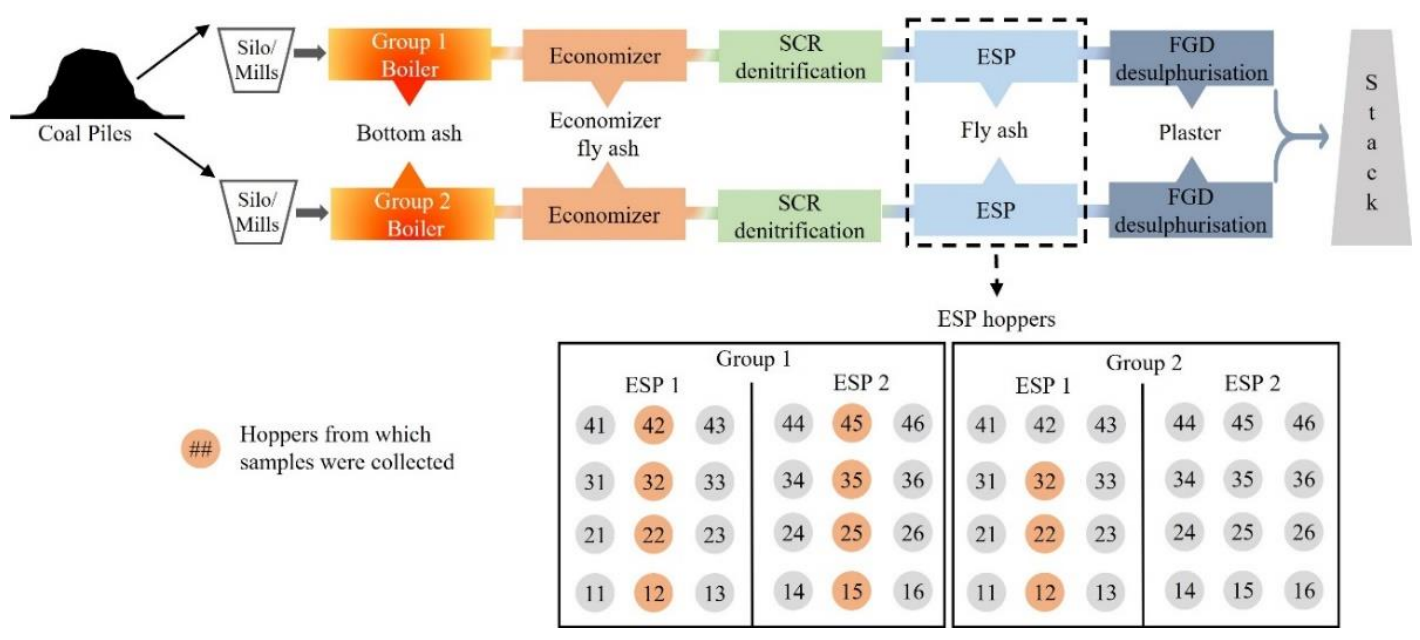

Figure 1. Scheme of Pego power plant and ESP arrays, with indications of where the samples were collected.

Over a period of a year, samples of feed coal (C), fly ash (FA), and bottom ash (BA) were collected approximately every three months. The samples were collected from Group 1 with the exception of the third campaign, which was conducted on Group 2 (Figure 1). Fly ash was collected from several locations in each sampling campaign, including from the economizer (ECO) and electrostatic precipitator (ESP) hoppers and silos. In the first campaign, FA samples from both Group 1 ESPs were collected in order to assess the possible lateral variations (Figure 1).

The nomenclatures of the samples were made by merging the sampling campaign ID (SX, where $\mathrm{X}$ corresponds to the number of the campaign) and the short form corresponding to the type of material and/or location (C: coal; BA: bottom ash; ECO: economizer; FA: fly ash; Si: silo). In the case of the FA from the ESP, the number of the bin where it was collected was added to the sample label.

\subsection{Analytical Methodologies}

\subsubsection{Chemical Analysis}

The proximate (moisture, ash, and volatile matter) and ultimate (carbon, hydrogen, and nitrogen) analyses of the bulk samples, feed coal, and combustion ashes were conducted in the certified laboratory of the Pego power plant.

The moisture (M), ash (A), and volatile matter (VM) of the feed coal samples were determined using a Thermogravimetric Analyzer, model TGA 701, according to the standard [54]. The concentrations of $\mathrm{C}, \mathrm{H}, \mathrm{N}$, and $\mathrm{S}$ were determined using LECO equipment, Tru Spec, following ASTM standards [55,56], and the oxygen was calculated by difference. The proximate analyses of the bulk ashes were performed following ISO standards [57-59]. The data were converted to other bases following the ISO guidelines [60], and the fixed carbon was calculated by difference [61]. 
The X-ray fluorescence (XRF), loss-on-ignition (LOI), inductively coupled plasma mass spectrometry (ICP-MS), and the elemental analysis were performed at Bureau Veritas Minerals, Vancouver, Canada (accredited laboratory NO.720, by ISO/IEC 17025:2005, using in-house certified reference material, or, in its absence, the samples were certified against internationally certified reference materials, such as the CANMET and USGS standards).

For the major and minor oxide determination via XRF, the samples were fused using a lithium borate fusion mixture. The LOI was determined by roasting a sample split at $1000{ }^{\circ} \mathrm{C}$. The total sulfur $\left(\mathrm{S}_{\mathrm{t}}\right)$ and carbon $\left(\mathrm{C}_{\mathrm{t}}\right)$, the graphite carbon $\left(\mathrm{C}_{\mathrm{gra}}\right)$, and the inorganic carbon $\left(\mathrm{C}_{\mathrm{CO} 2}\right)$ were determined using Leco equipment. For the $\mathrm{C}_{t}$ and $\mathrm{S}_{\mathrm{t}}$, an induction flux was added to the sample, which was then ignited in an induction furnace. The gases released were read in an infrared spectrometric cell and were attributed to carbon and sulfur, in all their forms. The graphitic carbon is determined in the residue after the leaching of the samples with $\mathrm{HCl}$, followed by ignition at $500{ }^{\circ} \mathrm{C}$, while the inorganic carbon is determined by directly measuring the $\mathrm{CO}_{2}$ gas evolved into the LECO analyzer in a prepared sample split-leached with perchloric acid. The organic carbon $\left(\mathrm{C}_{\mathrm{org}}\right)$ is determined by difference, wherein: $\mathrm{C}_{\text {org }}=\mathrm{C}_{\mathrm{t}}-\mathrm{C}_{\mathrm{CO} 2}-\mathrm{C}_{\text {gra }}$.

For the rare earth and refractory element determination via inductively coupled plasma mass spectrometry (ICP-MS), the samples were fused in a $\mathrm{LiBO}_{2} / \mathrm{Li}_{2} \mathrm{~B}_{4} \mathrm{O}_{7}$ flux and dissolved with ACS-grade nitric acid. This method was chosen since it enables the dissolution of the most resistant phases and the better recovery of the elements [62]. The Sc was not determined since it could be compromised by the spectral interferences of certain elements, such as Si [63].

\subsubsection{X-ray Diffraction (XRD)}

The identification of the mineralogical phases was carried out by XRD in the School of Biological, Earth and Environmental Sciences of the University of New South Wales (Sydney, Australia). Prior to the XRD analysis, the coal samples were ashed in a low temperature radio-frequency oxygen plasma asher. The ashing was performed at a low temperature (typically $120^{\circ} \mathrm{C}$ ) in a stream of activated oxygen under a partial vacuum under an applied radio frequency field. The coal samples were previously ground to a nominal particle size of $212 \mu \mathrm{m}$, and approximately $1 \mathrm{~g}$ was weighed out into each of two petri dishes. The ashing was continued until a constant weight was achieved. No prior treatment of the ash samples was necessary. For the XRD analysis, each sample was lightly pressed into a sample holder. The samples were run on a Empyrean X-ray diffractometer (Malvern Panalytical, Worcestershire, UK), using cobalt K $\alpha$ radiation, at tube settings of $45 \mathrm{kV}$ and $40 \mathrm{~mA}$. To minimize the effects of the sample inhomogeneity, the sample was spun throughout the data acquisition. The pattern was acquired over an angular range, from $3^{\circ} 2 \theta$ to $80^{\circ} 2 \theta$, at a step interval of $0.013^{\circ} 2 \theta$, for a scan time of $45 \mathrm{~min}$. Prior to the quantitative analysis, a qualitative phase identification was carried out using HighScore Plus (Malvern Panalytical, Worcestershire, UK), in conjunction with the ICCD pattern diffraction database. The quantitative analysis was performed using Siroquant ${ }^{\mathrm{TM}}$ (Sietronics Pty. Ltd., Canberra, Australia), a least squares full-pattern-matching Rietveld procedure, developed by the CSIRO [64].

\subsubsection{Petrography}

The petrographic analyses were performed on pellets with randomly oriented particles, prepared according to ISO standard procedures [65], using a Microscope Leica DM4500P equipped with a $\times 50$ oil objective (combined magnification of $\times 500$ ), controlled by the software, Fossil (Hilgers Technisches Büro, Königswinter, Germany). The maceral composition of the feed coals was performed by point-counting, following the standard [66] and nomenclature guidelines from the International Committee for Coal and Organic Petrology (ICCP) [67-70]. The mean random reflectances $\left(\mathrm{R}_{\mathrm{r}} \%\right)$ were measured in vitrinite macerals (collotelinite) as a parameter for the rank determination, as recommend by the ICCP [67]. 
The point-count analyses were also conducted on pellets of bulk coal combustion ashes to quantify the morphotypes, adapting the nomenclature defined by Hower [71].

\subsubsection{Scanning Electron Microscopy and Energy-Dispersive X-ray Spectroscopy (SEM/EDS)}

The SEM/EDS experiments were performed at the Materials Centre of the University of Porto, Portugal (CEMUP), using an FEI Quanta 400 FEGESEM/EDAX Genesis X4M. The equipment was operated at $15 \mathrm{kV}$ in high vacuum mode, with a manual aperture and an instrument-specific 4.5-beam spot-size setting. To improve the analysis quality under high vacuum conditions, the polished blocks were previously covered by sputtering a thin carbon film coating, and they were then fixed to the sample holder using double-sided adhesive carbon tape.

The tracking of the lanthanides, $\mathrm{Y}$ and Sc, in the coal combustion ashes (FA and BA) was performed using the method from Valentim et al. [72]. Although this method has been proven effective for the identification of the REE-bearing phases, it is time consuming and expensive. For these reasons, it was applied only on the ashes from the first sampling campaign (S1).

\subsubsection{Laser Diffraction}

The particle size distribution (PSD) determination via laser diffraction was determined at the Faculty of Engineering of the University of Porto (FEUP), using the Mastersizer 2000 (Malvern Panalytical, Worcestershire, UK). The equipment was coupled to a Hydro 2000 G, which enables measurements to be made in aqueous dispersions. IGEPAL was employed as a dispersant, and the PSD was determined through the Mie theory by comparison with the standard silica 1.0, with a refractive index (RI) of 1.544. The samples of BA and economizer FA were previously manually sieved at below $500 \mu \mathrm{m}$.

\subsubsection{Physical Separations}

The mechanical sieving and magnetic separation trials were completed at the Faculty of Sciences of the University of Porto. Firstly, the ash samples were dried in an oven at $30{ }^{\circ} \mathrm{C}$ until constant weight, and then sieved using a sieve shaker Retsch AS200 (Verder Scientific, Hope Valley, UK) and two sets of standard test sieves from Retsch $(200 \times 50 \mathrm{~mm})$, with the following nominal apertures: (a) 150, 75, 45, and $25 \mu \mathrm{m}(100,200,325$ and 500 mesh, respectively) for the fly ashes; and, (b) 4, 2, and $1 \mathrm{~mm}$, and 500, 250, 125, 90, and $63 \mu \mathrm{m}(5$, $10,18,35,60,120,170$, and 230 mesh, respectively) for the BA. The sieves were chosen based on the ash characteristics (BA is typically coarser than FA) and on previous research using similar materials [72-74]. For each trial, $20 \mathrm{~g}$ of sample was sieved during $30 \mathrm{~min}$, using an amplitude of $70 \%$. Additionally, fractions $<45 \mu \mathrm{m}$ from the selected FA samples were also mechanically wet-sieved using a clamping cover with a nozzle and a collecting pan with an outlet, respectively, at the top and the bottom of a standard sieve with a nominal aperture of $25 \mu \mathrm{m}$. The system was kept running until the water flowed out clean. The subsamples obtained were dried in an oven at $30^{\circ} \mathrm{C}$ until reaching a constant weight.

The magnetic fraction (MF) was collected via wet separation using a manual ferrite magnet. The solid/liquid ratio used was 0.01 (100 $\mathrm{g}$ to $10 \mathrm{~L})$. The sample was initially mixed for $5 \mathrm{~min}$ at $250 \mathrm{rpm}$ using a laboratory mixer, SCILOGEX OS20-S, to promote the deagglomeration of the particles. After that, the velocity was reduced to $150 \mathrm{rpm}$ and maintained this way during the procedure to avoid settling. The samples were dried in an oven at $60^{\circ} \mathrm{C}$ until they reached a constant weight.

\subsubsection{REE Classification, Patterns, and Anomalies}

In the current study, the threefold classification proposed by Seredin and Dai [18] is used, which divides the rare earth elements into: light (LREY; La through Sm), middle (Eu through Dy plus Y), and heavy (Ho through Lu). Nevertheless, the assessment of the REE distribution in ashes through the LREE/HREE ratio was calculated considering that the LREEs included La through Sm, and the heavy rare HREEs included Eu to Lu, in order 
to be comparable with previous studies (e.g., [13]). For the evaluation of the potential of coal combustion ashes as REE raw material, the classification of Seredin [50], based on the supply and demand forecasts of individual REEs, was used.

The normalization to the upper continental crust (UCC), besides being needed to eliminate the Oddo-Harkins effect (zig-zag shape), can provide information about the enrichment patterns and anomalies of individual elements that can be used to assess the REE differentiation during coal combustion $[18,23,41,75]$. Furthermore, it can provide information about the analysis quality. Thus, the values were normalized to UCC, N, and the decoupling of $\mathrm{Ce}, \mathrm{Eu}$, and $\mathrm{Gd}$ was quantified according to the equations in $[32,75,76]$ :

$$
\begin{gathered}
\mathrm{Eu}_{\mathrm{N}} / \mathrm{Eu}_{\mathrm{N}}^{*}=\mathrm{Eu}_{\mathrm{N}} /\left[\left(\mathrm{Sm}_{\mathrm{N}} \times 0.67\right)+\left(\mathrm{Tb}_{\mathrm{N}} \times 0.33\right)\right] \\
\mathrm{Ce}_{\mathrm{N}} / \mathrm{Ce}_{\mathrm{N}}^{*}=\mathrm{Ce}_{\mathrm{N}} /\left[\left(\mathrm{La}_{\mathrm{N}} \times 0.5\right)+\left(\mathrm{Pr}_{\mathrm{N}} \times 0.5\right)\right] \\
\mathrm{Gd}_{\mathrm{N}} / \mathrm{Gd}_{\mathrm{N}}^{*}=\mathrm{Gd}_{\mathrm{N}} /\left[\left(\mathrm{Sm}_{\mathrm{N}} \times 0.33\right)+\left(\mathrm{Tb}_{\mathrm{N}} \times 0.67\right)\right]
\end{gathered}
$$

\section{Results}

\subsection{General Characterization}

\subsubsection{Feed Coals}

Table 1 lists the results for the proximate and ultimate analyses (wt. \%), the gross calorific values (GCV, MJ/Kg), and the carbon forms (wt. \%) of the feed coals. The samples present low-to-medium ash contents, up to a $20 \mathrm{wt} . \%$ dry basis [77], low sulfur $(<1 \mathrm{wt.} \%)$ [78], and an average gross calorific value of $30.21 \mathrm{MJ} / \mathrm{Kg}$.

\begin{tabular}{|c|c|c|c|c|c|c|c|c|c|}
\hline & S1-C & $\mathrm{S} 2-\mathrm{C}_{1}$ & $\mathrm{~S} 2-\mathrm{C}_{2}$ & S3- $C_{1}$ & S3- $C_{2}$ & $S 4-C_{1}$ & $\mathrm{~S} 4-\mathrm{C}_{2}$ & Average & $\mathrm{CV}$ \\
\hline \multicolumn{10}{|c|}{ Proximate analysis } \\
\hline $\mathrm{M}_{\mathrm{ad}}$ & 6.24 & 6.04 & 8.31 & 6.20 & 6.88 & 6.71 & 5.84 & 6.60 & 11.72 \\
\hline $\mathrm{A}_{\mathrm{d}}$ & 3.28 & 7.39 & 8.25 & 10.19 & 9.12 & 10.10 & 9.01 & 8.19 & 26.88 \\
\hline $\mathrm{V}_{\text {daf }}$ & 39.82 & 41.74 & 42.37 & 41.16 & 41.88 & 41.70 & 40.44 & 41.30 & 2.00 \\
\hline $\mathrm{FC}_{\text {daf }}$ & 60.18 & 58.26 & 57.63 & 58.84 & 58.12 & 58.30 & 59.56 & 58.70 & 1.41 \\
\hline \multicolumn{10}{|c|}{ Ultimate analysis } \\
\hline $\mathrm{S}_{\mathrm{d}}$ & 0.52 & 0.79 & 0.79 & 0.66 & 0.63 & 0.73 & 0.72 & 0.69 & 12.92 \\
\hline $\mathrm{C}_{\text {daf }}$ & 80.34 & 77.21 & 77.30 & 79.72 & 78.62 & 78.53 & 80.30 & 78.86 & 1.54 \\
\hline $\mathrm{H}_{\mathrm{daf}}$ & 6.20 & 5.93 & 6.22 & 6.18 & 6.17 & 6.07 & 6.08 & 6.12 & 1.55 \\
\hline $\mathrm{N}_{\mathrm{daf}}$ & 1.64 & 1.63 & 1.56 & 1.60 & 1.62 & 1.60 & 1.57 & 1.60 & 1.72 \\
\hline $\mathrm{O}_{\text {daf }}$ & 11.28 & 14.37 & 14.06 & 11.77 & 12.90 & 12.98 & 11.25 & 12.66 & 9.32 \\
\hline Atomic H/C & 0.92 & 0.92 & 0.96 & 0.92 & 0.93 & 0.92 & 0.90 & 0.93 & 1.78 \\
\hline Atomic $\mathrm{O} / \mathrm{C}$ & 0.11 & 0.14 & 0.14 & 0.11 & 0.12 & 0.12 & 0.11 & 0.12 & 10.87 \\
\hline $\mathrm{GCV}_{\mathrm{d}}$ & 29.19 & 30.21 & 28.94 & 29.46 & 29.68 & 29.66 & 29.78 & 29.56 & 1.30 \\
\hline \multicolumn{10}{|l|}{ Carbon forms } \\
\hline $\mathrm{C}_{\mathrm{t}}$ & 72.45 & 66.48 & 64.49 & 65.37 & 65.09 & 65.32 & 67.93 & 66.73 & 3.83 \\
\hline $\mathrm{C}_{\text {org }}$ & 72.42 & 66.43 & 64.44 & 65.31 & 65.02 & 65.28 & 67.87 & 66.68 & 3.85 \\
\hline $\mathrm{C}_{\mathrm{CO} 2}$ & 0.01 & 0.04 & 0.03 & 0.01 & 0.03 & 0.03 & 0.02 & 0.02 & 54.67 \\
\hline $\mathrm{C}_{\text {gra }}$ & 0.07 & 0.02 & 0.06 & 0.15 & 0.15 & 0.05 & 0.15 & 0.09 & 55.43 \\
\hline
\end{tabular}

Table 1. Proximate and ultimate analyses (wt. \%), gross calorific values (GCV, MJ/Kg), and forms of carbon (wt. \%) of the feed coals.

SX-Cx: coal sample, (C) corresponding to X sampling campaign; CV: coefficient of variation; M: moisture; A: ash yield; V: volatile matter; $\mathrm{S}$ : sulfur; C: carbon; $\mathrm{H}$ : hydrogen; $\mathrm{N}$ : nitrogen; $\mathrm{GCV}$ : gross calorific value; $\mathrm{C}_{\mathrm{t}}$ : total carbon; org: organic; gra: graphitic; $\mathrm{CO}_{2}$ : inorganic; ad: air-dry basis; d: dry basis; daf: dry and ash-free basis.

The ash yield among the coals analyzed ranged from 3.28 to $10.19 \mathrm{wt} . \%$, corresponding to a coefficient of variation (CV) of $27 \%$. Excluding S1-C, which presents a significantly lower ash yield, the $\mathrm{CV}$ would be lowered to $11 \%$. Elements that are usually associated with mineral matter in coals, such as REEs [79], are expected to be found in lower concentrations in the aforementioned sample.

The atomic ratios $\mathrm{H} / \mathrm{C}$ and $\mathrm{O} / \mathrm{C}$ are compatible with the bituminous coal rank [80] and, according to the ASTM D388 [81], all coals can be classified as high-volatile A bitu- 
minous coal. As expected, the carbon is predominantly organic (>99 wt.\%, Table 1). The differences in the carbon content from the elemental analysis and the fixed carbon (FC) may originate from the loss of carbon as hydrocarbon in the volatile matter during the proximate analysis [82].

The results of the petrographic analyses conducted on the feed coals are presented in Table 2. The nomenclature used follows the guidelines of the ICCP [67-69]. The feed coals have moderate-to-high vitrinite contents (77-83 vol. \% mineral-ash-free basis (mmf); [77]), with collodetrinite being dominant, at up to 67 vol. \% of the total vitrinite content. The inertinite group represents 14-19 vol. \% mmf, and liptinite was found in minor amounts, ranging from 3 to $5 \mathrm{vol}$. \% mmf. The feed coal S1-C presents the lowest observable mineral matter content (1.6 vol. \%, Table 2), which agrees with the ash yield (Table 1), and which differs from the other coal samples by the absence of fines resulting from coal beneficiation [83-85]. On the basis of the vitrinite reflectance, all of the feed coals analyzed can be classified as "medium rank D" (bituminous), except of S2-C2, which is a low rank A (sub-bituminous) borderline to medium rank D [77].

Table 2. Petrographic analysis results for the feed coals.

\begin{tabular}{|c|c|c|c|c|c|c|c|}
\hline & S1-C & $\mathrm{S} 2-\mathrm{C}_{1}$ & $\mathrm{~S} 2-\mathrm{C}_{2}$ & S3- $C_{1}$ & $\mathrm{~S} 3-\mathrm{C}_{2}$ & S4- $C_{1}$ & $\mathrm{~S} 4-\mathrm{C}_{2}$ \\
\hline Vitrinite (vol. \%) & 79.8 & 76.9 & 72.6 & 78.2 & 74.9 & 75.5 & 71.7 \\
\hline Telinite & 1.8 & 2.9 & 2.6 & 1.3 & 2.6 & 1.3 & 2.5 \\
\hline Collotelinite & 11.0 & 10.6 & 20.6 & 14.4 & 14.1 & 19.3 & 10.0 \\
\hline Vitrodetrinite & 4.1 & 5.8 & 8.7 & 5.2 & 7.0 & 4.9 & 7.6 \\
\hline Collodetrinite & 53.5 & 47.0 & 32.0 & 47.8 & 43.0 & 41.6 & 44.5 \\
\hline Corpogelenite & 9.2 & 10.0 & 8.0 & 9.1 & 8.2 & 7.8 & 6.9 \\
\hline Gelenite & 0.2 & 0.5 & 0.7 & 0.4 & 0.0 & 0.5 & 0.2 \\
\hline Inertinite (vol. \%) & 15.7 & 15.3 & 17.2 & 13.1 & 12.8 & 15.6 & 17.2 \\
\hline Fusinite & 1.8 & 0.9 & 3.1 & 2.8 & 2.6 & 1.8 & 1.6 \\
\hline Semifusinite & 7.5 & 3.6 & 5.2 & 3.9 & 2.9 & 5.3 & 5.1 \\
\hline Funginite & 0.4 & 0.4 & 0.7 & 0.0 & 0.2 & 0.2 & 0.5 \\
\hline Secretinite & 0.0 & 0.2 & 0.5 & 0.2 & 0.2 & 0.4 & 0.2 \\
\hline Macrinite & 2.5 & 3.8 & 2.6 & 3.2 & 2.0 & 2.0 & 3.4 \\
\hline Micrinite & 0.0 & 0.0 & 0.0 & 0.0 & 0.0 & 0.0 & 0.0 \\
\hline Inertodetrinite & 3.5 & 6.4 & 5.2 & 3.0 & 4.9 & 6.0 & 6.4 \\
\hline Liptinite (vol. \%) & 2.9 & 4.4 & 4.0 & 3.0 & 4.8 & 2.7 & 4.0 \\
\hline Cutinite & 0.4 & 0.5 & 1.2 & 0.9 & 0.9 & 0.5 & 0.4 \\
\hline Suberinite & 0.0 & 0.0 & 0.0 & 0.0 & 0.0 & 0.0 & 0.0 \\
\hline Sporinite & 0.6 & 1.3 & 0.5 & 0.9 & 1.1 & 0.7 & 0.9 \\
\hline Resinite & 0.6 & 0.7 & 1.2 & 0.4 & 0.9 & 0.0 & 0.0 \\
\hline Exsudatinite & 0.0 & 0.0 & 0.0 & 0.0 & 0.0 & 0.0 & 0.0 \\
\hline Chlorophyllinite & 0.0 & 0.0 & 0.0 & 0.0 & 0.0 & 0.0 & 0.0 \\
\hline Alginite & 0.0 & 0.0 & 0.0 & 0.0 & 0.0 & 0.0 & 0.0 \\
\hline Liptodetrinite & 1.4 & 1.8 & 1.2 & 0.7 & 1.8 & 1.5 & 2.7 \\
\hline Bituminite & 0.0 & 0.0 & 0.0 & 0.0 & 0.0 & 0.0 & 0.0 \\
\hline Mineral matter (vol. \%) & 1.6 & 3.5 & 5.9 & 5.8 & 7.5 & 6.2 & 7.1 \\
\hline Total reactive macerals (vol. \%) & 82.7 & 81.2 & 76.6 & 81.2 & 79.7 & 78.2 & 75.7 \\
\hline \multicolumn{8}{|l|}{ Vitrinite reflectance } \\
\hline Mean random reflectance ( $\mathrm{Rr} \%)$ & 0.53 & 0.55 & 0.48 & 0.58 & 0.55 & 0.53 & 0.57 \\
\hline Standard deviation & 0.06 & 0.05 & 0.04 & 0.05 & 0.05 & 0.04 & 0.07 \\
\hline Rank category & $\begin{array}{l}\text { Medium } \\
\text { rank D }\end{array}$ & $\begin{array}{c}\text { Medium } \\
\text { rank D }\end{array}$ & $\begin{array}{c}\text { Low rank } \\
\mathrm{A}\end{array}$ & $\begin{array}{l}\text { Medium } \\
\text { rank D }\end{array}$ & $\begin{array}{l}\text { Medium } \\
\text { rank D }\end{array}$ & $\begin{array}{l}\text { Medium } \\
\text { rank D }\end{array}$ & $\begin{array}{l}\text { Medium } \\
\text { rank D }\end{array}$ \\
\hline
\end{tabular}

SX-Cx: coal sample $(C)$ corresponding to $X$ sampling campaign.

The major and minor oxides (whole-coal basis; wt.\%), the loss-on-ignition (LOI; wt.\%), and the LTA mineralogy (wt. \%) of the feed coals are presented in Table 3. 
Table 3. Major oxides, LOI, and mineralogical results for feed coals (wt. \%).

\begin{tabular}{|c|c|c|c|c|c|c|c|}
\hline & S1-C & $S 2-C_{1}$ & $\mathrm{~S} 2-\mathrm{C}_{2}$ & S3- $C_{1}$ & $\mathrm{~S} 3-\mathrm{C}_{2}$ & $S 4-C_{1}$ & $S 4-C_{2}$ \\
\hline \multicolumn{8}{|l|}{ Major oxides } \\
\hline $\mathrm{SiO}_{2}$ & 1.76 & 4.78 & 3.97 & 6.94 & 5.72 & 5.64 & 5.11 \\
\hline $\mathrm{TiO}_{2}$ & $<0.01$ & 0.07 & 0.05 & 0.07 & 0.04 & 0.06 & 0.06 \\
\hline $\mathrm{Al}_{2} \mathrm{O}_{3}$ & 0.65 & 1.5 & 1.56 & 2.21 & 1.48 & 1.83 & 1.78 \\
\hline $\mathrm{Fe}_{2} \mathrm{O}_{3}$ & 0.05 & 0.53 & 1.08 & 0.71 & 0.84 & 0.56 & 0.41 \\
\hline $\mathrm{MnO}$ & $<0.01$ & $<0.01$ & $<0.01$ & $<0.01$ & $<0.01$ & $<0.01$ & $<0.01$ \\
\hline $\mathrm{CaO}$ & 0.06 & 0.11 & 0.19 & 0.13 & 0.11 & 0.14 & 0.12 \\
\hline $\mathrm{MgO}$ & $<0.01$ & $<0.01$ & $<0.01$ & 0.01 & $<0.01$ & $<0.01$ & $<0.01$ \\
\hline $\mathrm{Na}_{2} \mathrm{O}$ & $<0.01$ & $<0.01$ & 0.08 & $<0.01$ & $<0.01$ & $<0.01$ & $<0.01$ \\
\hline $\mathrm{K}_{2} \mathrm{O}$ & 0.04 & 0.14 & 0.14 & 0.23 & 0.12 & 0.18 & 0.19 \\
\hline $\mathrm{P}_{2} \mathrm{O}_{5}$ & 0.01 & $<0.01$ & $<0.01$ & 0.02 & $<0.01$ & $<0.01$ & $<0.01$ \\
\hline $\mathrm{SO}_{3}$ & 0.03 & 0.41 & 0.26 & 0.08 & 0.28 & 0.08 & 0.07 \\
\hline $\mathrm{Cr}_{2} \mathrm{O}_{3}$ & $<0.01$ & $<0.01$ & $<0.01$ & $<0.01$ & $<0.01$ & $<0.01$ & $<0.01$ \\
\hline $\mathrm{SiO}_{2} / \mathrm{Al}_{2} \mathrm{O}_{3}$ & 2.71 & 3.19 & 2.54 & 3.14 & 3.86 & 3.08 & 2.87 \\
\hline LOI & 97 & 91.5 & 91.7 & 88.2 & 90.8 & 90 & 91 \\
\hline \multicolumn{8}{|l|}{ LTA mineralogy } \\
\hline Quartz $\left(\mathrm{SiO}_{2}\right)$ & 31 & 35.9 & 37.7 & 30.6 & 41.6 & 38.7 & n.d. \\
\hline Albite $\left(\mathrm{NaAlSi}_{3} \mathrm{O}_{8}\right)$ & 0.6 & 0 & 0.8 & 1.5 & 0.2 & 0.7 & n.d. \\
\hline Hornblende $\left(\mathrm{Ca}_{2}\left(\mathrm{Mg}, \mathrm{Fe}^{2+}\right)_{4} \mathrm{Al}\left(\mathrm{Si}_{7} \mathrm{AlO}_{22}\right)(\mathrm{OH}, \mathrm{F})_{2}\right)$ & 0.8 & 0.8 & 0.5 & 0.8 & 0.7 & 0.4 & n.d. \\
\hline Muscovite $\left(\mathrm{KAl}_{2}\left(\mathrm{AlSi}_{3}\right) \mathrm{O}_{10}(\mathrm{OH})_{2}\right)$ & 4 & 9.4 & 6.3 & 8.9 & 7 & 8.4 & n.d. \\
\hline Illite $\left(\mathrm{K}_{1.5} \mathrm{Al}_{4}\left(\mathrm{Si}_{6.5} \mathrm{Al}_{1.5}\right) \mathrm{O}_{20}(\mathrm{OH})_{4}\right)$ & 4.2 & 6.1 & 9.8 & 12 & 6.5 & 7.9 & n.d. \\
\hline Kaolinite $\left(\mathrm{Al}_{2} \mathrm{Si}_{2} \mathrm{O}_{5}(\mathrm{OH})_{4}\right)$ & 45.5 & 27 & 22.6 & 26.9 & 27.8 & 25.6 & n.d. \\
\hline $\begin{array}{l}\text { Montmorillonite } \\
\left((\mathrm{Na}, \mathrm{Ca})_{0.33}(\mathrm{Al}, \mathrm{Mg})_{2}\left(\mathrm{Si}_{4} \mathrm{O}_{10}\right)(\mathrm{OH})_{2} \cdot \mathrm{nH}_{2} \mathrm{O}\right)\end{array}$ & 0.3 & 0.3 & 0.3 & 0.5 & 0.2 & 0 & n.d. \\
\hline Chlorite $\left((\mathrm{MgFeAl})_{6}(\mathrm{AlSi})_{4} \mathrm{O}_{10}(\mathrm{OH})_{8}\right)$ & 0.3 & 1.6 & 2 & 2.3 & 2.2 & 0.3 & n.d. \\
\hline Anatase $\left(\mathrm{TiO}_{2}\right)$ & 0.3 & 1 & 0.6 & 0.6 & 0.2 & 0.7 & n.d. \\
\hline Boehmite $(\mathrm{Al} \cdot \mathrm{O} \cdot \mathrm{OH})$ & 0.2 & 0.3 & 0.4 & 0.1 & 0.1 & 0.1 & n.d. \\
\hline Calcite $\left(\mathrm{CaCO}_{3}\right)$ & 0 & 0 & 0.1 & 0 & 0 & 0 & n.d. \\
\hline Siderite $\left(\mathrm{FeCO}_{3}\right)$ & 0.3 & 0 & 0.3 & 0.7 & 0.3 & 0 & n.d. \\
\hline Bassanite $\left(\mathrm{CaSO}_{4} \cdot 0.5 \mathrm{H}_{2} \mathrm{O}\right)$ & 0.7 & 0.5 & 2.4 & 0.5 & 2.1 & 1.2 & n.d. \\
\hline Gypsum $\left(\mathrm{CaSO}_{4} \cdot 2 \mathrm{H}_{2} \mathrm{O}\right)$ & 3.4 & 2.3 & 4.4 & 3.6 & 4.3 & 3.5 & n.d. \\
\hline Hexahydrite $\left(\mathrm{MgSO}_{4} \cdot 6 \mathrm{H}_{2} \mathrm{O}\right)$ & 2.3 & 1.2 & 1 & 1.7 & 2.2 & 4.2 & n.d. \\
\hline Jarosite $\left((\mathrm{K}, \mathrm{Na}) \mathrm{Fe}_{3}\left(\mathrm{SO}_{4}\right)_{2}(\mathrm{OH})_{6}\right)$ & 1.1 & 3.5 & 1.4 & 3 & 1.2 & 2.3 & n.d. \\
\hline Alunogen $\left(\mathrm{Al}_{2}\left(\mathrm{SO}_{4}\right)_{3} \cdot 17 \mathrm{H}_{2} \mathrm{O}\right)$ & 3.3 & 8.5 & 3.3 & 4.5 & 0.6 & 4 & n.d. \\
\hline Tschermigite $\left(\mathrm{NH}_{4} \mathrm{Al}\left(\mathrm{SO}_{4}\right)_{2} \cdot 12 \mathrm{H}_{2} \mathrm{O}\right.$ & 0 & 0.2 & 0.5 & 0 & 0.8 & 0 & n.d. \\
\hline Apatite $\left(\mathrm{Ca}_{5} \mathrm{~F}\left(\mathrm{PO}_{4}\right)_{3}\right)$ & 0.6 & 0.1 & 1.2 & 0.6 & 1.2 & 0.5 & n.d. \\
\hline Pyrite $\left(\mathrm{FeS}_{2}\right)$ & 1.2 & 1.3 & 4.5 & 1.2 & 0.9 & 1.7 & n.d. \\
\hline
\end{tabular}

SX-Cx: coal sample (C) corresponding to X sampling campaign; LOI: loss-on-ignition; n.d.: not determined.

The predominant oxides are $\mathrm{SiO}_{2}$ and $\mathrm{Al}_{2} \mathrm{O}_{3}$, with averages of 4.85 and 1.57 wt.\%, respectively. The average ratio of $\mathrm{SiO}_{2} / \mathrm{Al}_{2} \mathrm{O}_{3}$ (3.06) is higher than the theoretical ratio of kaolinite (1.18), indicating the presence of quartz [86]. Minor amounts of $\mathrm{Fe}_{2} \mathrm{O}_{3}(0.05$ to 1.09 wt.\%), $\mathrm{SO}_{3}$ (0.03 to 0.41 wt. \%), $\mathrm{K}_{2} \mathrm{O}$ (0.04 to 0.23 wt.\%), $\mathrm{CaO}$ (0.06 to 0.19 wt.\%), and $\mathrm{TiO}_{2}$ (up to $0.07 \mathrm{wt} . \%$ ) were detected, while the remaining elements were below the detection limits (bdl: $<0.01 \mathrm{wt} \%$ ). The coal from the first campaign (S1-C) shows lower contents of all oxides, compared to the other samples studied.

The LTA of feed coals are mainly composed of silicates ( $\geq 80 \mathrm{wt} . \%)$, with quartz and kaolinite being predominant, representing, on average, $65 \mathrm{wt} . \%$ of the total mineral matter (Table 3). The kaolinite content is markedly higher in S1-C, relative to the other samples (>17 wt.\%). Observations under SEM/EDS showed massive aggregates of kaolinite in this sample (Figure 2A,B), which were not detected in the other samples. 


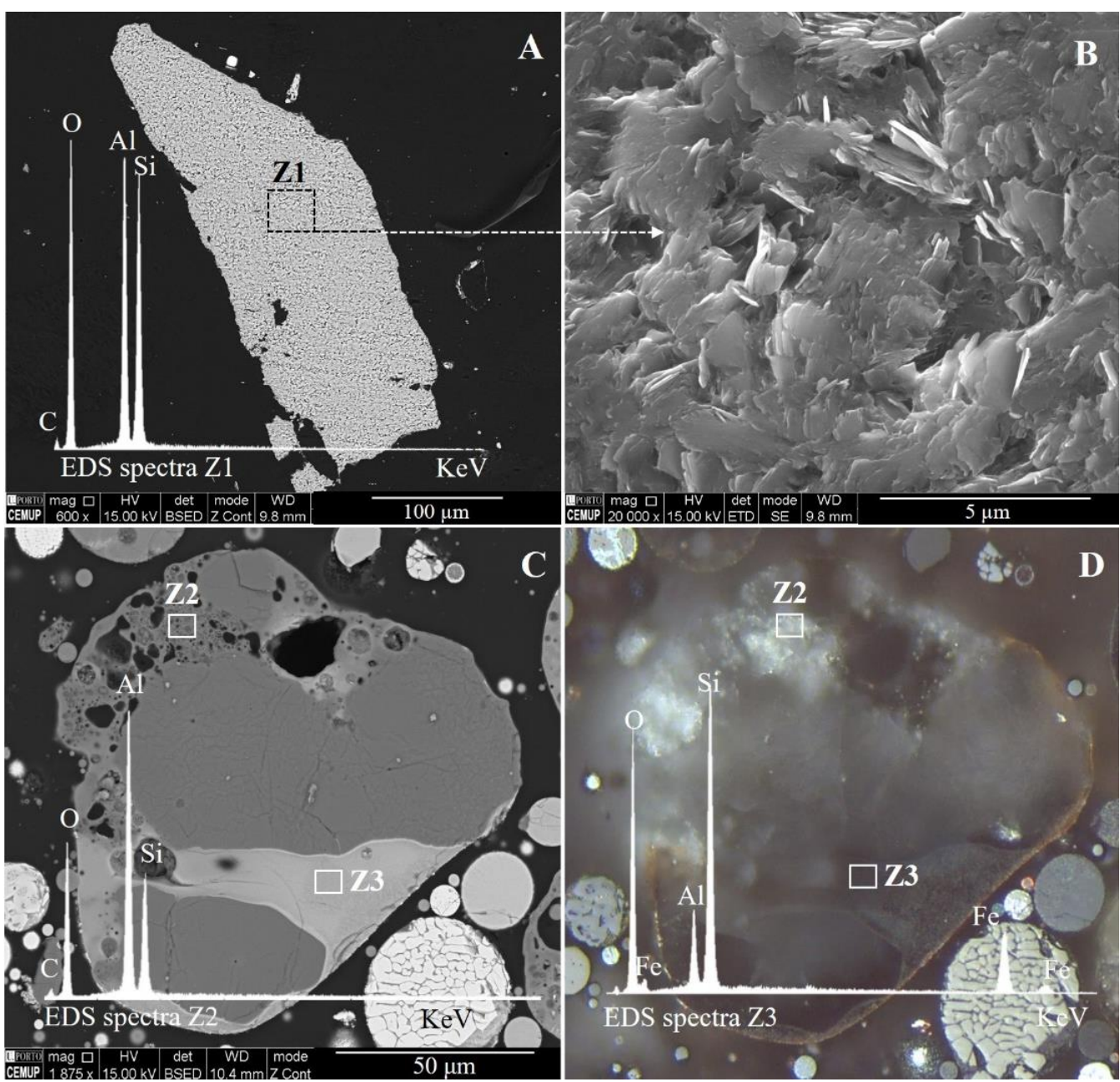

Figure 2. Massive kaolinite aggregate observed under SEM/EDS in coal sample from campaign S1: (A) whole-particle view ( $\times 600$; BSE mode) and respective EDS spectra; and (B) magnification of dashed square area in "a" showing the kaolinite lamellae $(\times 20,000$; SE mode). Particle from fly ash sample of first ESP row observed under SEM/EDS (C) optical microscopy, and (D) EDS spectra relative to $\mathrm{Z} 2$ and $\mathrm{Z3}$, noted in the microphotographs.

Sulfates represented between 11 to $16 \mathrm{wt}$ \% of the mineral matter. However, bassanite and other sulphates, such as hexahydrite, alunogen, and tschermigite are usually considered to be artifacts from the ashing process [87]. The presence of gypsum (2.3-4.4 wt.\%) may suggest that some of the bassanite (0.5-2.4 wt.\%) is due to the partial dehydration of preexisting gypsum and/or the reaction of organic sulfur with organically associated calcium. During the SEM/EDS experiments, no gypsum was detected, so it is assumed that is also an artifact from the ashing process. Jarosite probably resulted from the sulfide oxidation, such as pyrite, during coal exposure or storage [88]. Pyrite was detected in contents that ranged from 0.9 to $4.5 \mathrm{wt}$.\%. Other minerals were detected in low concentrations, such as apatite (0.6-1.2 wt.\%), anatase (0.3-1.0 wt.\%), and boehmite (0.1-0.4 wt.\%). Siderite was detected in four samples $\left(\mathrm{S} 1-\mathrm{C}, \mathrm{S} 1-\mathrm{C}_{2}, \mathrm{~S} 3-\mathrm{C}_{1}\right.$, and $\left.\mathrm{S} 3-\mathrm{C}_{2}\right)$, in concentrations ranging from 0.3 to $0.7 \mathrm{wt} . \%$, while calcite was detected in a single coal $\left(\mathrm{S} 2-\mathrm{C}_{2}\right)$, with a content of $0.1 \mathrm{wt} . \%$.

\subsubsection{Coal Combustion Ashes}

Texturally, BA and ECO FA are easily distinguished from the FA collected on the ESP (Figure 3). The first two are coarser, with particles predominantly in the silt-size range, avg. 67 vol.\% (Table 4). In the FA from the ESP, particles within the silt-size of 71 vol. $\%$ avg. dominate, but it also contains particles in the size ranges of sand and clay: 23 and 6 vol.\%, 
respectively. A large range of $\mathrm{D}_{90}-\mathrm{D}_{10}$ is verified for the BA and the ECO FA (avg. $\left.259 \mu \mathrm{m}\right)$; however, the lower span (avg. 2.5) indicates a better homogeneity in comparison to the ESP FA (avg. span of 5) (Table 4). Nevertheless, it must be considered that those samples were sieved at $<500 \mu \mathrm{m}$ before the analysis, excluding, on average, $60 \mathrm{wt} . \%$ of the material. Still, according to Folk and Ward [89], the ashes analyzed are poorly sorted $(1<\mathrm{SD}<2)$ to very poorly sorted $(2<\mathrm{SD}<4)$.

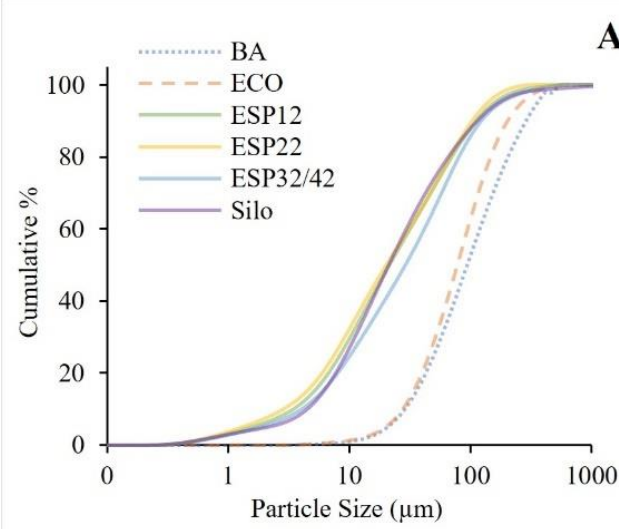

A
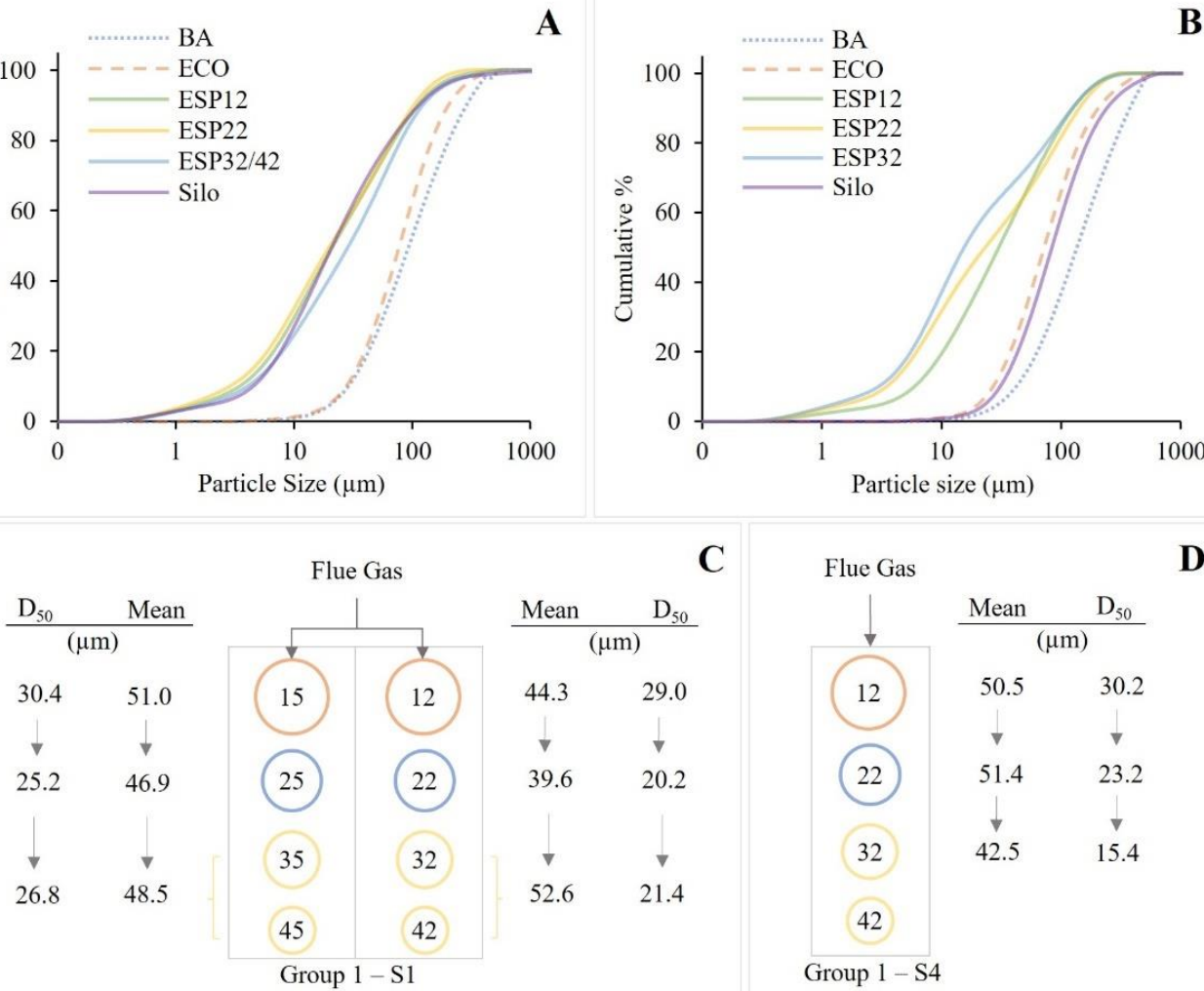

C

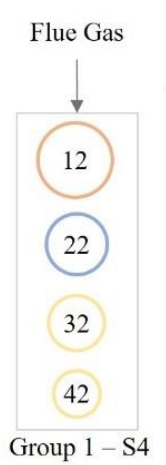

D

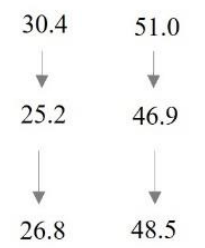

Group $1-\mathrm{S}$

Figure 3. Particle size distributions for ashes from (A) S1, only ESP rows 12-32/42 included, and (B) S4. Scheme illustrating the variations of mean particle sizes and D50 inside ESP on (C) S1, and (D) S4.

Table 4. Particle size characteristics of the FA and BA samples analyzed by laser diffraction.

\begin{tabular}{|c|c|c|c|c|c|c|c|c|c|c|c|}
\hline Campaign & Sample & $\begin{array}{c}\text { Mean } \\
(\mu \mathrm{m})\end{array}$ & $\begin{array}{c}D_{10} \\
(\mu \mathrm{m})\end{array}$ & $\begin{array}{l}D_{50} \\
(\mu \mathrm{m})\end{array}$ & $\begin{array}{c}D_{90} \\
(\mu \mathrm{m})\end{array}$ & $\begin{array}{c}\mathrm{D}_{90}-\mathrm{D}_{10} \\
(\mu \mathrm{m})\end{array}$ & Span & $\begin{array}{l}\text { SD } \\
(\varphi)\end{array}$ & $\begin{array}{c}\text { Clay vol.\% } \\
(<2 \mu \mathrm{m})\end{array}$ & $\begin{array}{l}\text { Silt vol.\% } \\
(2-63 \mu \mathrm{m})\end{array}$ & $\begin{array}{c}\text { Sand vol.\% } \\
(63-2000 \mu \mathrm{m})\end{array}$ \\
\hline \multirow[t]{9}{*}{ S1 } & BA & 147.7 & 33.05 & 108.3 & 331.7 & 298.7 & 2.8 & 1.3 & 0.0 & 31.7 & 68.3 \\
\hline & ECO & 115.3 & 31.55 & 89.37 & 232.1 & 200.6 & 2.2 & 1.1 & 0.0 & 37.2 & 62.8 \\
\hline & ESP12 & 44.3 & 3.5 & 21.4 & 111.2 & 107.8 & 5.0 & 2.0 & 6.7 & 73.1 & 20.3 \\
\hline & ESP15 & 51.0 & 4.7 & 30.4 & 125.9 & 121.2 & 4.0 & 1.9 & 4.8 & 69.8 & 25.4 \\
\hline & ESP22 & 39.6 & 2.9 & 20.2 & 103.5 & 100.6 & 5.0 & 2.0 & 8.0 & 72.6 & 19.4 \\
\hline & ESP25 & 46.9 & 4.1 & 25.2 & 115.0 & 111.0 & 4.4 & 1.9 & 5.8 & 72.6 & 21.6 \\
\hline & ESP32/42 & 52.6 & 4.1 & 29.0 & 122.5 & 118.4 & 4.1 & 2.0 & 5.8 & 69.8 & 24.4 \\
\hline & ESP35/45 & 48.5 & 4.6 & 26.8 & 125.6 & 121.0 & 4.5 & 1.9 & 5.0 & 70.4 & 24.5 \\
\hline & Silo & 51.4 & 4.5 & 21.1 & 113.6 & 109.1 & 5.2 & 1.9 & 5.1 & 76.1 & 18.9 \\
\hline \multirow[t]{6}{*}{ S4 } & BA & 174.0 & 42.0 & 135.5 & 375.2 & 333.3 & 2.5 & 1.2 & 0.0 & 22.9 & 77.1 \\
\hline & ECO & 112.7 & 30.9 & 82.7 & 234.7 & 203.8 & 2.5 & 1.1 & 0.0 & 40.9 & 59.1 \\
\hline & ESP12 & 50.5 & 5.9 & 30.2 & 126.0 & 120.0 & 4.0 & 1.7 & 3.8 & 71.2 & 25.0 \\
\hline & ESP22 & 51.4 & 3.5 & 23.2 & 141.8 & 138.3 & 6.0 & 2.1 & 6.3 & 66.1 & 27.6 \\
\hline & ESP32 & 42.5 & 3.0 & 15.4 & 123.4 & 120.4 & 7.8 & 2.2 & 7.7 & 70.6 & 21.7 \\
\hline & Silo & 116.0 & 31.0 & 83.7 & 240.0 & 209.1 & 2.5 & 1.2 & 0.0 & 40.5 & 59.5 \\
\hline
\end{tabular}


The mean particle size (volume weighted) decreases as follows: BA (avg. $167 \mu \mathrm{m})>$ ECO (avg. $114 \mu \mathrm{m})>$ ESP (avg. $48 \mu \mathrm{m}$ ). The $\mathrm{D}_{50}$ follows the same trend (Table 4). The decrease in the particle sizes, from the ECO to the the ESP, was expected, since the first line of any system of pollution control tends to separate the coarsest particles from the flue gas stream, concentrating the finer particles in the ESP $[20,47,73,74]$. The ashes from the silo in S1 present an average particle size similar to the ESP FA, while, in S4, it is closer to the ECO FA. Both ashes were redirected to the silo, and the sampling could have been affected by a heterogeneous distribution inside the structure.

Usually, a decrease in the particle size towards the back rows of the ESP array is expected, but slight variations were observed. In S1, opposite trends were observed towards the ESP back rows (Figure 3C): (a) in the 12-32/42 rows, the mean particle size increase by $8.3 \mu \mathrm{m}$, while, (b) in the 15-35/45 rows, it decreases by $3.3 \mu \mathrm{m}$. In both, the lowest mean particle size is found in the middle row (Table 4). In S4, the mean particle size decreases towards the ESP back rows $(8 \mu \mathrm{m})$, such as the 15-35/45 rows from S1, and D50 reduces approx. 50\% from the first to the last row (Figure 3D).

The results of the proximate analysis, and the sulfur, carbon forms, and major oxides, are listed in Table 5. The ashes have moisture contents varying from 0.04 to $0.59 \mathrm{wt} . \%$, ash values between 92.27 and $99.89 \mathrm{wt} . \%$, sulfur up to $0.49 \mathrm{wt} . \%$, and carbon from 0.22 to $6.32 \mathrm{wt} . \%$. The contents of the sulfur and carbon increase as follows: BA $<$ ECO FA $<$ ESP FA. The carbon distribution is corroborated by the char vol. \%, determined in the ash petrographic analysis (Table 7).

Table 5. Proximate and ultimate analyses and carbon form results for the bulk ashes (wt. \%).

\begin{tabular}{|c|c|c|c|c|c|c|c|c|}
\hline Campaign & Sample & $\mathbf{M}_{\mathrm{ad}}$ & $\mathbf{A}_{\mathrm{d}}$ & $S_{t}$ & $C_{t}$ & $C_{\text {org }}$ & $\mathrm{C}_{\text {gra }}$ & $\mathrm{C}_{\mathrm{Co} 2}$ \\
\hline \multirow[t]{9}{*}{ S1 } & BA & 0.12 & 99.63 & $<0.02$ & 0.35 & 0.19 & 0.09 & 0.24 \\
\hline & ECO & 0.12 & 98.31 & 0.05 & 1.69 & 0.81 & 0.85 & 0.10 \\
\hline & ESP12 & 0.27 & 94.25 & 0.13 & 5.51 & 2.75 & 2.74 & 0.09 \\
\hline & ESP15 & 0.28 & 95.33 & 0.13 & 4.38 & 1.86 & 2.51 & $<0.02$ \\
\hline & ESP22 & 0.27 & 93.67 & 0.14 & 5.92 & 2.82 & 3.09 & 0.07 \\
\hline & ESP25 & 0.27 & 94.6 & 0.2 & 4.92 & 2.28 & 2.63 & 0.02 \\
\hline & ESP32/42 & 0.26 & 93.45 & 0.12 & 6.17 & 2.83 & 3.31 & 0.10 \\
\hline & ESP35/45 & 0.31 & 94.35 & 0.15 & 5.26 & 2.29 & 2.95 & 0.07 \\
\hline & Silo & 0.17 & 95.88 & 0.13 & 3.03 & 0.97 & 2.06 & $<0.02$ \\
\hline \multirow[t]{5}{*}{ S2 } & ECO & 0.32 & 98.42 & 0.11 & 1.37 & 0.76 & 0.59 & 0.05 \\
\hline & ESP12 & 0.3 & 97.44 & 0.17 & 2.36 & 1.44 & 0.9 & 0.04 \\
\hline & ESP22 & 0.37 & 97.1 & 0.29 & 2.3 & 1.44 & 0.85 & 0.04 \\
\hline & ESP32/42 & 0.37 & 95.88 & 0.33 & 2.98 & 1.55 & 1.42 & 0.04 \\
\hline & Silo & 0.25 & 97.36 & 0.22 & 2.66 & 1.79 & 0.86 & 0.06 \\
\hline \multirow[t]{5}{*}{ S3 } & $\mathrm{BA}$ & 0.08 & 99.52 & $<0.02$ & 0.35 & 0.29 & 0.03 & 0.1 \\
\hline & ESP12 & 0.32 & 96.15 & 0.14 & 3.46 & 1.98 & 1.47 & 0.05 \\
\hline & ESP22 & 0.37 & 95.09 & 0.21 & 4.25 & 2.35 & 1.89 & $<0.02$ \\
\hline & ESP32 & 0.59 & 95 & 0.49 & 3.43 & 1.77 & 1.66 & $<0.02$ \\
\hline & Silo & 0.25 & 95.13 & 0.15 & 4.17 & 1.94 & 2.21 & 0.04 \\
\hline \multirow[t]{6}{*}{ S4 } & BA & 0.04 & 99.89 & $<0.02$ & 0.22 & 0.16 & 0.05 & 0.04 \\
\hline & ECO & 0.11 & 94.32 & 0.04 & 5.32 & 1.49 & 3.79 & 0.16 \\
\hline & ESP12 & 0.35 & 93.26 & 0.15 & 6.32 & 2.27 & 4.02 & 0.09 \\
\hline & ESP22 & 0.35 & 92.27 & 0.23 & 6.12 & 1.92 & 4.19 & 0.04 \\
\hline & ESP32 & 0.48 & 93.37 & 0.4 & 5.41 & 1.83 & 3.57 & $<0.02$ \\
\hline & Silo & 0.25 & 94.32 & 0.17 & 5.32 & 1.93 & 3.36 & 0.09 \\
\hline Minimum & & 0.04 & 92.27 & $<0.02$ & 0.22 & 0.16 & 0.03 & $<0.02$ \\
\hline Average & & 0.27 & 95.63 & 0.19 & 3.60 & 1.61 & 1.97 & 0.06 \\
\hline Maximum & & 0.59 & 99.89 & 0.49 & 6.32 & 2.83 & 4.19 & 0.24 \\
\hline CV (\%) & & 45.60 & 2.22 & 60.51 & 52.78 & 47.10 & 64.84 & 81.63 \\
\hline
\end{tabular}


Except in S1, the sulfur tends to increase towards the back of the ESP, at an average of 2.7 times. Similar trends were found for $\mathrm{SO}_{3}$ (Table 4). This was expected given the sulfur volatility and the cooler flue gas temperatures in the back end of the ESP $[39,47]$. In terms of the carbon distribution inside the ESP, in S1 and S2, there is an increase towards the back hoppers, which agrees with the reported data [47,90-92], while the reverse is observed in the two remaining campaigns. The variations found can be related to the changes in the combustion conditions. The carbon in FA is predominantly organic and elemental, which together account for $94-100 \mathrm{wt} . \%$ of the total carbon, while inorganic carbon is residual, accounting for $<6 \mathrm{wt} . \%$. In BA, the organic carbon is the dominant form (37-64 wt.\%) and is up to three times more abundant than elemental carbon (S1-BA and S3-BA).

The ashes are mainly composed of $\mathrm{SiO}_{2}$ and $\mathrm{Al}_{2} \mathrm{O}_{3}$, which, together, represent up to 84.35 wt. $\%$ of all oxides (Table 6). Those are followed by $\mathrm{Fe}_{2} \mathrm{O}_{3}(6.29-9.01 \mathrm{wt} . \%), \mathrm{K}_{2} \mathrm{O}$ (1.33-2.45 wt.\%), $\mathrm{CaO}(1.24-2.38$ wt.\%), $\mathrm{MgO}$ (1.13-2.04 wt.\%), and some minor oxides ( $\leq 1$ wt.\%), such as $\mathrm{Na}_{2} \mathrm{O}, \mathrm{TiO}_{2}, \mathrm{SO}_{3}, \mathrm{P}_{2} \mathrm{O}_{5}, \mathrm{MnO}$, and $\mathrm{Cr}_{2} \mathrm{O}_{3}$ (Table 6). The ashes from $\mathrm{S} 1$ present similar compositions to the remaining ashes analyzed, even though the feed coal from which they were derived presented the lowest oxide concentrations (Table 3). Furthermore, they show slightly higher average concentrations of $\mathrm{K}_{2} \mathrm{O}$ and $\mathrm{MgO}$, at 2.27 and $1.88 \mathrm{wt} . \%$, respectively. The $\mathrm{CaO}$ and $\mathrm{NaO}$ are slightly more concentrated in $\mathrm{S} 2$, at 1.96 and $1.29 \mathrm{wt} . \%$, respectively, which is related to the higher concentrations observed in the respective feed coals (Table 3). However, this is not verified for $\mathrm{Fe}_{2} \mathrm{O}_{3}$ and $\mathrm{SO}_{3}$, which are more concentrated in ashes from $\mathrm{S} 4$, at 8.19 and $0.40 \mathrm{wt} . \%$, respectively, while the feed coals from S2 presented higher average concentrations, at 0.81 and $0.33 \mathrm{wt} . \%$, respectively.

The bottom ashes and fly ashes from the ECO present similar compositions to the ESP fly ashes, but they are generally richer in $\mathrm{SiO}_{2}$ and $\mathrm{Fe}_{2} \mathrm{O}_{3}$, and slightly poor in $\mathrm{Al}_{2} \mathrm{O}_{3}, \mathrm{~K}_{2} \mathrm{O}$, $\mathrm{MgO}, \mathrm{Na}_{2} \mathrm{O}, \mathrm{P}_{2} \mathrm{O}_{5}, \mathrm{SO}_{3}$, and $\mathrm{TiO}_{2}$ (Table 6). The ashes from the ECO present slightly higher $\mathrm{SiO}_{2} / \mathrm{Al}_{2} \mathrm{O}_{3}$ ratios, which is probably due to the higher contents of quartz, as was verified by XRD and petrography (Table 7). Despite some variations, the oxide concentration tends to slightly increase to the back of the ESP, while the $\mathrm{SiO}_{2}$ and $\mathrm{SiO}_{2} / \mathrm{Al}_{2} \mathrm{O}_{3}$ ratio behaves in reverse, which can be related to the decreasing quartz content (Table 6). Similar to sulfur, $\mathrm{P}$ and $\mathrm{Na}$ tend to volatilize during combustion, but their condensation on FA is triggered by the decrease in the temperature in the ESP, so lower concentrations in BA and an increase in the ESP are expected [39]. The uneven distribution of nonvolatile elements (e.g., $\mathrm{Si}, \mathrm{Fe}$, $\mathrm{Al}$, and $\mathrm{K}$ ) must be related to their modes of occurrence, such as the association to the glass phase (Figure 8). The oxides, $\mathrm{P}_{2} \mathrm{O}_{5}, \mathrm{SO}_{3}$ and $\mathrm{Cr}_{2} \mathrm{O}_{3}$, presented the highest coefficient of variation $(\mathrm{CV}>25 \%)$. In the case of $\mathrm{Cr}_{2} \mathrm{O}_{3}$, the value is largely influenced by an anomalous concentration found on the sample, S2-ECO.

According to Vassilev and Vassileva [93], all the ashes analyzed belong to the sialic type, with a medium acid tendency. The authors attribute this type of acidity to coals enriched in clay and mica, quartz, and minor amounts of authigenic sulfates, carbonates, and sulfides, which is corroborated by the respective feed coal mineralogy (Table 3). From the perspective of the cement industry, the ashes are classified as F, and where the LOI is greater than $6 \%$, additional tests would be required to approve its use [94]. 
Table 6. Major oxide results for the bulk coal ashes (wt.\%).

\begin{tabular}{|c|c|c|c|c|c|c|c|c|c|c|c|c|c|c|c|}
\hline Campaign & Sample & $\mathrm{SiO}_{2}$ & $\mathrm{TiO}_{2}$ & $\mathrm{Al}_{2} \mathrm{O}_{3}$ & $\mathrm{Fe}_{2} \mathrm{O}_{3}$ & $\mathrm{MnO}$ & $\mathrm{CaO}$ & $\mathrm{MgO}$ & $\mathrm{Na}_{2} \mathrm{O}$ & $\mathrm{K}_{2} \mathrm{O}$ & $\mathrm{P}_{2} \mathrm{O}_{5}$ & $\mathrm{SO}_{3}$ & $\mathrm{Cr}_{2} \mathrm{O}_{3}$ & LOI & $\mathrm{SiO}_{2} / \mathrm{Al}_{2} \mathrm{O}_{3}$ \\
\hline \multirow[t]{7}{*}{ S1 } & $\mathrm{BA}$ & 66.07 & 0.81 & 18.28 & 7.95 & 0.08 & 1.50 & 1.87 & 1.04 & 2.11 & 0.14 & 0.03 & 0.02 & 0.10 & 3.61 \\
\hline & ECO & 67.77 & 0.66 & 15.15 & 8.13 & 0.08 & 1.81 & 1.86 & 1.10 & 1.72 & 0.13 & 0.07 & 0.02 & 1.51 & 4.47 \\
\hline & ESP12 & 59.65 & 0.88 & 20.22 & 6.36 & 0.06 & 1.34 & 1.83 & 1.07 & 2.37 & 0.16 & 0.13 & 0.02 & 5.89 & 2.95 \\
\hline & ESP22 & 58.81 & 0.89 & 20.58 & 6.31 & 0.06 & 1.24 & 1.79 & 1.06 & 2.45 & 0.16 & 0.12 & 0.02 & 6.49 & 2.86 \\
\hline & ESP25 & 58.74 & 0.88 & 20.31 & 6.55 & 0.06 & 1.61 & 1.91 & 1.14 & 2.26 & 0.18 & 0.37 & 0.02 & 5.99 & 2.89 \\
\hline & ESP32/42 & 59.77 & 0.85 & 19.62 & 6.29 & 0.06 & 1.30 & 1.76 & 1.04 & 2.33 & 0.15 & 0.13 & 0.02 & 6.68 & 3.05 \\
\hline & ESP35/45 & 59.23 & 0.87 & 19.91 & 6.65 & 0.07 & 1.62 & 1.93 & 1.14 & 2.26 & 0.17 & 0.15 & 0.02 & 5.96 & 2.97 \\
\hline \multirow[t]{5}{*}{ S2 } & $\mathrm{ECO}$ & 68.25 & 0.67 & 15.40 & 8.42 & 0.06 & 1.49 & 1.13 & 0.73 & 1.33 & 0.11 & 0.33 & 0.27 & 1.81 & 4.43 \\
\hline & ESP12 & 62.52 & 0.84 & 19.16 & 7.89 & 0.04 & 2.02 & 1.25 & 1.33 & 1.78 & 0.13 & 0.30 & 0.02 & 2.72 & 3.26 \\
\hline & ESP22 & 57.22 & 0.95 & 21.76 & 8.32 & 0.05 & 2.38 & 1.61 & 1.62 & 2.10 & 0.21 & 0.43 & 0.02 & 3.32 & 2.63 \\
\hline & ESP32/42 & 56.65 & 0.98 & 22.18 & 7.62 & 0.06 & 1.88 & 1.86 & 1.43 & 2.38 & 0.23 & 0.37 & 0.02 & 4.33 & 2.55 \\
\hline & Silo & 61.07 & 0.87 & 19.65 & 8.13 & 0.04 & 2.05 & 1.36 & 1.32 & 1.88 & 0.14 & 0.35 & 0.02 & 3.12 & 3.11 \\
\hline \multirow[t]{3}{*}{ S3 } & BA & 65.89 & 0.77 & 18.03 & 8.85 & 0.07 & 1.44 & 1.57 & 0.94 & 1.89 & 0.14 & 0.09 & 0.02 & 0.30 & 3.65 \\
\hline & ESP12 & 61.02 & 0.86 & 19.94 & 7.70 & 0.06 & 1.33 & 1.58 & 1.06 & 2.10 & 0.15 & 0.25 & 0.02 & 3.93 & 3.06 \\
\hline & ESP22 & 57.20 & 0.94 & 21.63 & 7.93 & 0.06 & 1.38 & 1.78 & 1.20 & 2.31 & 0.19 & 0.30 & 0.02 & 5.05 & 2.64 \\
\hline \multirow[t]{6}{*}{ S4 } & BA & 66.56 & 0.79 & 17.60 & 9.01 & 0.07 & 1.56 & 1.65 & 0.94 & 1.88 & 0.10 & 0.03 & 0.02 & -0.20 & 3.78 \\
\hline & ECO & 63.11 & 0.70 & 16.23 & 8.37 & 0.07 & 1.76 & 1.63 & 0.87 & 1.70 & 0.11 & 0.05 & 0.01 & 5.38 & 3.89 \\
\hline & ESP12 & 58.71 & 0.83 & 18.97 & 7.82 & 0.06 & 1.57 & 1.76 & 1.06 & 2.08 & 0.13 & 0.34 & 0.02 & 6.66 & 3.10 \\
\hline & ESP22 & 54.79 & 0.90 & 20.52 & 7.92 & 0.07 & 1.60 & 1.95 & 1.16 & 2.25 & 0.17 & 0.56 & 0.02 & 8.09 & 2.67 \\
\hline & ESP32 & 53.82 & 0.94 & 21.49 & 8.15 & 0.07 & 1.67 & 2.04 & 1.23 & 2.34 & 0.22 & 0.98 & 0.02 & 7.03 & 2.50 \\
\hline & Silo & 58.94 & 0.85 & 19.31 & 7.84 & 0.06 & 1.62 & 1.83 & 1.06 & 2.14 & 0.14 & 0.42 & 0.02 & 5.76 & 3.05 \\
\hline Minimum & & 53.82 & 0.66 & 15.15 & 6.29 & 0.04 & 1.24 & 1.13 & 0.73 & 1.33 & 0.10 & 0.03 & 0.01 & -0.20 & 3.55 \\
\hline Average & & 60.52 & 0.85 & 19.50 & 7.70 & 0.06 & 1.60 & 1.74 & 1.12 & 2.11 & 0.16 & 0.27 & 0.03 & 4.34 & 3.10 \\
\hline Maximum & & 68.25 & 0.99 & 22.35 & 9.01 & 0.08 & 2.38 & 2.04 & 1.62 & 2.45 & 0.28 & 0.98 & 0.27 & 8.09 & 3.05 \\
\hline CV $(\%)$ & & 6.5 & 9.8 & 9.7 & 10.2 & 15.3 & 16.4 & 13.0 & 15.7 & 12.9 & 24.7 & 76.1 & 163.3 & 51.3 & 0.67 \\
\hline
\end{tabular}

LOI: loss-on-ignition; BA: bottom ash; ECO: economizer; ESP: electrostatic precipitator; CV: coefficient of variation. 
Table 7. X-ray diffraction (wt.\%) and petrographic (vol.\%) results for bulk coal combustion ashes.

\begin{tabular}{|c|c|c|c|c|c|c|c|c|c|c|c|c|c|c|c|c|c|c|c|c|c|c|c|c|c|}
\hline & \multicolumn{9}{|l|}{ S1 } & \multicolumn{5}{|l|}{ S2 } & \multicolumn{5}{|l|}{ S3 } & \multicolumn{6}{|l|}{ S4 } \\
\hline & \multirow{2}{*}{ BA } & \multirow{2}{*}{ ECO } & \multicolumn{6}{|c|}{ ESP } & \multirow{2}{*}{ Silo } & \multirow{2}{*}{ ECO } & \multicolumn{3}{|c|}{ ESP } & \multirow{2}{*}{ Silo } & \multirow{2}{*}{ BA } & \multicolumn{3}{|c|}{ ESP } & \multirow{2}{*}{ Silo } & \multirow{2}{*}{ BA } & \multirow{2}{*}{ ECO } & \multicolumn{3}{|c|}{ ESP } & \multirow{2}{*}{ Silo } \\
\hline & & & 12 & 15 & 22 & 25 & $32 / 42$ & $35 / 45$ & & & 12 & 22 & $32 / 42$ & & & 12 & 22 & $32 / 42$ & & & & 12 & 22 & $32 / 42$ & \\
\hline \multicolumn{26}{|l|}{ XRD (wt. \%) } \\
\hline Quartz $\left(\mathrm{SiO}_{2}\right)$ & 11.5 & 24.8 & 12.5 & 16.1 & 10.3 & 12.8 & 12.5 & 13.6 & 12.3 & 21.4 & 21.9 & 11.0 & 10.1 & 20.4 & 19.5 & 16.1 & 11.1 & 6.8 & 16.7 & 8.8 & 18.0 & 12.0 & 8.1 & 7.0 & 13.5 \\
\hline Cristobalite $\left(\mathrm{SiO}_{2}\right)$ & 0.3 & 0.1 & 0.0 & 0.1 & 0.0 & 0.0 & 0.1 & 0.0 & 0.1 & 0.0 & 0.1 & 0.0 & 0.1 & 0.1 & 0.1 & 0.1 & 0.1 & 0.0 & 0.1 & 0.8 & 0.0 & 0.0 & 0.0 & 0.0 & 0.1 \\
\hline Mullite $\left(\mathrm{Al}_{6} \mathrm{Si}_{2} \mathrm{O}_{13}\right)$ & 6.6 & 8.3 & 4.7 & 5.2 & 4.4 & 5.1 & 4.6 & 5.3 & 5.1 & 6.7 & 7.5 & 4.4 & 5.2 & 6.9 & 12.5 & 5.8 & 5.2 & 4.6 & 6.6 & 6.6 & 4.6 & 4.1 & 3.1 & 3.5 & 5.8 \\
\hline Cordierite $\left(\mathrm{Mg}_{2} \mathrm{Al}_{\left.4 \mathrm{Si}_{5} \mathrm{O}_{18}\right)}\right.$ & 0.2 & 0.1 & 0.2 & 0.1 & 0.1 & 0.2 & 0.0 & 0.1 & 0.1 & 0.1 & 0.3 & 0.1 & 0.1 & 0.2 & 0.1 & 0.2 & 0.1 & 0.1 & 0.1 & 0.5 & 0.2 & 0.1 & 0.1 & 0.1 & 0.1 \\
\hline Albite $\left(\mathrm{NaAlSi}_{3} \mathrm{O}_{8}\right)$ & 0.0 & 1.4 & 0.9 & 0.9 & 0.9 & 0.0 & 1.5 & 1.4 & 1.4 & 0.1 & 2.2 & 1.9 & 1.2 & 1.8 & 1.9 & 1.4 & 2.0 & 0.8 & 1.0 & 0.5 & 0.1 & 1.9 & 1.6 & 0.8 & 1.0 \\
\hline Diopside $\left.\left((\mathrm{Ca}, \mathrm{Mg}, \mathrm{Fe})_{2} \mathrm{Si}_{2} \mathrm{O}_{6}\right)\right)$ & 0.1 & 0.7 & 0.8 & 1.3 & 0.4 & 0.0 & 0.2 & 1.2 & 1.4 & 0.3 & 0.5 & 0.8 & 1.9 & 1.1 & 0.5 & 0.3 & 0.8 & 1.3 & 0.2 & 0.0 & 0.4 & 0.5 & 0.6 & 0.7 & 0.4 \\
\hline Calcium aluminate $\left(\mathrm{Ca}_{3} \mathrm{Al}_{2} \mathrm{O}_{6}\right)$ & 0.1 & 0.5 & 0.1 & 0.0 & 0.1 & 0.1 & 0.1 & 0.0 & 0.2 & 0.0 & 0.4 & 0.5 & 0.3 & 0.2 & 0.1 & 0.3 & 0.3 & 0.3 & 0.2 & 0.1 & 0.1 & 0.2 & 0.4 & 0.3 & 0.3 \\
\hline Rutile $\left(\mathrm{TiO}_{2}\right)$ & 0.1 & 0.5 & 0.3 & 0.4 & 0.2 & 0.1 & 0.2 & 0.2 & 0.0 & 0.0 & 0.4 & 0.1 & 0.1 & 0.3 & 0.3 & 0.4 & 0.2 & 0.0 & 0.4 & 0.1 & 0.2 & 0.2 & 0.0 & 0.1 & 0.4 \\
\hline Hematite $\left(\mathrm{Fe}_{2} \mathrm{O}_{3}\right)$ & 0.6 & 0.6 & 0.7 & 1.0 & 0.6 & 0.7 & 0.6 & 0.9 & 0.5 & 1.4 & 0.8 & 0.5 & 0.6 & 1.8 & 2.3 & 0.7 & 0.7 & 0.5 & 0.6 & 1.1 & 1.1 & 0.6 & 0.5 & 0.4 & 0.9 \\
\hline Maghemite $\left(\mathrm{Fe}_{2} \mathrm{O}_{3}\right)$ & 1.0 & 1.2 & 0.2 & 0.5 & 0.4 & 1.3 & 0.4 & 0.5 & 0.5 & 2.3 & 0.0 & 0.1 & 0.3 & 0.7 & 0.7 & 0.5 & 0.5 & 0.3 & 0.3 & 2.0 & 3.2 & 0.4 & 0.3 & 0.2 & 0.5 \\
\hline Magnetite $\left(\mathrm{Fe}_{3} \mathrm{O}_{4}\right)$ & 0.0 & 2.0 & 0.9 & 1.5 & 0.9 & 1.1 & 1.0 & 0.0 & 0.0 & 0.5 & 2.0 & 1.7 & 0.8 & 0.2 & 0.5 & 0.8 & 0.5 & 0.8 & 1.5 & 0.1 & 0.4 & 0.6 & 0.8 & 0.7 & 1.1 \\
\hline Magnesioferrite $\left(\mathrm{MgFe}_{2} \mathrm{O}_{4}\right)$ & 0.0 & 0.2 & 0.4 & 0.7 & 0.0 & 0.0 & 0.0 & 1.0 & 0.5 & 0.0 & 0.2 & 0.2 & 0.0 & 0.7 & 0.0 & 0.2 & 0.3 & 0.0 & 0.2 & 0.0 & 0.0 & 0.5 & 0.0 & 0.2 & 0.3 \\
\hline Hercynite $\left(\mathrm{FeAl}_{2} \mathrm{O}_{4}\right)$ & 0.0 & 0.4 & 0.0 & 0.2 & 0.0 & 0.1 & 0.0 & 0.0 & 0.0 & 0.0 & 0.0 & 0.0 & 0.1 & 0.0 & 0.1 & 0.0 & 0.1 & 0.1 & 0.0 & 0.3 & 0.0 & 0.0 & 0.0 & 0.0 & 0.1 \\
\hline Calcite $\left(\mathrm{CaCO}_{3}\right)$ & 0.0 & 0.1 & 0.1 & 0.1 & 0.1 & 0.1 & 0.1 & 0.1 & 0.1 & 0.0 & 0.2 & 0.2 & 0.2 & 0.2 & 0.1 & 0.1 & 0.2 & 0.2 & 0.0 & 0.0 & 0.0 & 0.2 & 0.2 & 0.2 & 0.2 \\
\hline Gypsum $\left(\mathrm{CaSO}_{4} \cdot 2 \mathrm{H}_{2} \mathrm{O}\right)$ & 1.5 & 0.4 & 0.3 & 0.3 & 0.2 & 1.6 & 0.2 & 0.6 & 0.3 & 2.8 & 0.5 & 0.3 & 0.3 & 0.5 & 0.5 & 0.4 & 0.3 & 0.3 & 0.2 & 0.2 & 1.0 & 0.4 & 0.4 & 0.3 & 0.6 \\
\hline Anhydrite $\left(\mathrm{CaSO}_{4}\right)$ & 0.0 & 0.1 & 0.1 & 0.1 & 0.1 & 0.2 & 0.1 & 0.1 & 0.1 & 0.1 & 0.2 & 0.3 & 0.3 & 0.2 & 0.0 & 0.2 & 0.2 & 0.3 & 0.1 & 0.2 & 0.3 & 0.1 & 0.2 & 0.3 & 0.3 \\
\hline Amorphous & 77.9 & 58.5 & 78.0 & 71.4 & 81.1 & 76.8 & 78.4 & 75.0 & 77.3 & 64.2 & 63.0 & 78.0 & 78.6 & 64.7 & 60.7 & 72.7 & 77.3 & 83.7 & 71.7 & 78.8 & 70.4 & 78.3 & 83.8 & 85.4 & 74.7 \\
\hline Glass & 78.9 & 71.2 & 76.1 & 72.0 & 80.2 & 77.6 & 79.8 & 77.4 & 79.6 & 72.2 & 76.3 & 83.1 & 83.6 & 79.0 & 80.5 & 78.8 & 84.2 & 77.3 & 76.8 & 79.6 & 71.2 & 74.3 & 75.9 & 79.3 & 76.9 \\
\hline Quartz & 4.8 & 14.2 & 4.0 & 7.4 & 4.2 & 4.8 & 1.5 & 4.8 & 5.4 & 12.4 & 9.5 & 4.8 & 5.7 & 8.0 & 6.5 & 9.0 & 3.4 & 1.8 & 6.0 & 5.9 & 9.0 & 5.6 & 4.7 & 4.1 & 5.5 \\
\hline Mulllite & 8.8 & 1.5 & 0.8 & 0.6 & 1.0 & 0.8 & 1.0 & 0.4 & 0.4 & 1.2 & 0.0 & 0.2 & 0.2 & 0.0 & 5.9 & 1.0 & 0.2 & 0.0 & 0.8 & 6.3 & 0.8 & 0.6 & 0.3 & 0.5 & 0.8 \\
\hline Anorthite & 0.0 & 0.0 & 0.0 & 0.0 & 0.0 & 0.0 & 0.0 & 0.0 & 0.0 & 0.0 & 0.0 & 0.0 & 0.0 & 0.0 & 0.0 & 0.0 & 0.0 & 0.0 & 0.0 & 0.4 & 0.0 & 0.0 & 0.0 & 0.0 & 0.0 \\
\hline Ferrosphere & 2.6 & 3.7 & 3.2 & 2.8 & 1.6 & 1.8 & 2.2 & 1.6 & 1.6 & 3.4 & 4.4 & 2.2 & 2.9 & 4.0 & 2.5 & 2.0 & 2.2 & 4.3 & 2.4 & 2.9 & 2.6 & 3.0 & 2.1 & 2.4 & 2.5 \\
\hline Other & 2.4 & 2.0 & 3.8 & 3.2 & 2.0 & 1.8 & 2.0 & 3.0 & 2.8 & 1.0 & 2.2 & 1.8 & 0.7 & 2.0 & 1.3 & 1.2 & 0.6 & 3.7 & 2.4 & 3.1 & 1.8 & 1.4 & 1.6 & 2.4 & 3.7 \\
\hline Partially baked & 2.2 & 5.2 & 1.3 & 3.0 & 1.6 & 2.4 & 2.5 & 1.2 & 3.2 & 6.4 & 3.4 & 2.4 & 1.2 & 4.0 & 2.1 & 3.0 & 1.0 & 0.7 & 4.0 & 1.4 & 5.6 & 3.8 & 0.3 & 0.5 & 2.9 \\
\hline Char & 0.0 & 2.0 & 10.8 & 11.0 & 9.0 & 10.9 & 10.6 & 11.0 & 7.0 & 2.8 & 4.2 & 5.3 & 5.5 & 3.0 & 0.0 & 4.6 & 8.0 & 11.7 & 7.2 & 0.4 & 9.0 & 11.2 & 15.3 & 10.2 & 7.8 \\
\hline Unburned coal & 0.0 & 0.0 & 0.0 & 0.0 & 0.4 & 0.0 & 0.5 & 0.6 & 0.0 & 0.6 & 0.0 & 0.2 & 0.2 & 0.0 & 1.1 & 0.4 & 0.4 & 0.5 & 0.4 & 0.0 & 0.0 & 0.2 & 0.0 & 0.5 & 0.0 \\
\hline
\end{tabular}

SX: sampling campign; BA: bottom ash; ECO: economizer fly ash; ESP: electrostatic precipitator. 
The ashes are mainly composed of an amorphous phase (58.2-85.4 wt.\%; Table 7), which encompasses aluminosilicate glass (71.2-84.2 vol.\%), char (up to $15.3 \mathrm{wt} . \%$ ), and unburned coal (up to $1.1 \mathrm{wt} \%$ ), identified via petrographic analysis (Table 7). SEM/EDS investigations enabled the discrimination of two main types of glass [84]: (a) A major class, with chemical compositions similar to illite/smectite, occurring as large masses in BA and as subrounded/rounded particles in FA (Figure 2-Z3); and (b) A minor class, essentially composed of $\mathrm{Al}$ and $\mathrm{Si}$, generally occurring with irregular shapes and spongy textures, in FA and BA (Figure 2-Z2). The latter is similar to the vesicular Al-Si glass, described by Wang et al. [4], in BA samples from the pulverized-coal Luzhou Chuannan Power Station. Previously, Matjie et al. [95] had already described an Al-Si glass with a honeycomb structure, but in clinker/coarse ash from a Sasol-Lurgi fixed bed dry bottom, which was attributed to kaolinite dehydration. Kolker et al. [96], via a SHRIMP-RG ion microprobe analysis on FA from U.S. power plants, describe a glass almost exclusively composed of Al-Si depleted in REEs. The Al-Si glass identified under the current research is easily distinguished under petrographic analysis by its bright white color and its spongy/vesicular texture (Figure 2D). The remaining glasses exhibit a wide range of colors but, in general, are less porous. The presence of $\mathrm{Ca}$ has been associated with yellowish colors [97], while iron seems to be responsible for a dark brown color (Figure 2D). In the current work, this brownish glass was more often observed in BA during petrographic analysis, suggesting that the glasses in BA are richer in Fe.

Quartz and mullite are the dominant crystalline phases, corresponding to $6.8-24.8 \mathrm{wt} \%$ and 3.1-12.5 wt.\%, respectively (Table 7). Because of its high melting temperature (approx. $1800^{\circ} \mathrm{C}$ ), quartz is expected to pass through combustion without major alterations [87]. Nevertheless, surface reaction rims, which are characterized by the loss of the quartz translucence and the presence of bubbles, were observed in several grains. Mullite is mainly derived from kaolinite and can be incorporated into the matrix of the glass spheres, e.g., $[4,98,99]$. The small nature of FA particles limits the identification of mullite during petrographic analysis, and they are, therefore, undervalued (Table 7). Economizer FA presents the highest contents of quartz and partially baked particles (Table 7). The coarser nature of these particles must control their early retention in the particle control system. The content of quartz and mullite tend to decrease towards to the back of the ESP, contrary to the amorphous phase trend (Table 7). The increase in the amorphous phase trend corresponds not only to the increase in the glass content, but also to the char (Table 7). These trends are consistent with previous works (e.g., [100]).

Iron oxides, such as magnetite, hematite, and maghemite, represent approx. $2 \mathrm{wt} . \%$, on average, of the FA. The economizer FA presents higher maghemite contents (1.2-3.2 wt.\%) than the BA and ESP FA, which may be the result of magnetite oxidation. These phases result from the decomposition of the Fe-bearing phases present in feed coals (Table 3), such as pyrite and siderite, and are found embedded in Fe-rich aluminosilicate glass, which are the main components of ferrospheres [101]. Some of them react with $\mathrm{MgO}$-originating magnesioferrite (up to $0.2 \mathrm{wt} \%$ ), a distinctive mineral of the magnesiaferrosphere morphotypes [97,102], which are counted as "others" in this study's petrographic analysis (Table 7).

\subsection{Rare Earth Elements and Other Refractory Elements in Feed Coals and Respective Ashes 3.2.1. Contents, Distribution, and Partitioning}

The results regarding the trace elements (ppm), enrichment patterns, and anomalies of the individual REEs in feed coals, and the respective bulk combustion ashes, are available in the Supplementary Information, Tables S1 and S2.

The concentrations of REEs ( $\sum$ REE) in the feed coals range from 6.97 to 23.15 ppm, corresponding to an overall coefficient of variation (CV) of $26.9 \%$ (Table S1). The average REE concentration (18.70 ppm) is significantly lower than the average concentrations reported for the world hard coals (WHC): 68.41 ppm; U.S. coals: 62.09 ppm; and Chinese coals: 138.47 ppm [31,103,104]. The feed coal with the smallest ash yield $(3.28$ wt.\%, 
S1-C) also presents the lowest $\sum$ REE, at $6.97 \mathrm{ppm}$, suggesting an association of REEs with the mineral matter, which is corroborated by the positive correlation between REEs and the ash yield (Figure 4A). Excluding S1-C, the REE content changed slightly over time, corresponding to an average of $20.65 \mathrm{ppm}$, and a CV of $7.9 \%$.
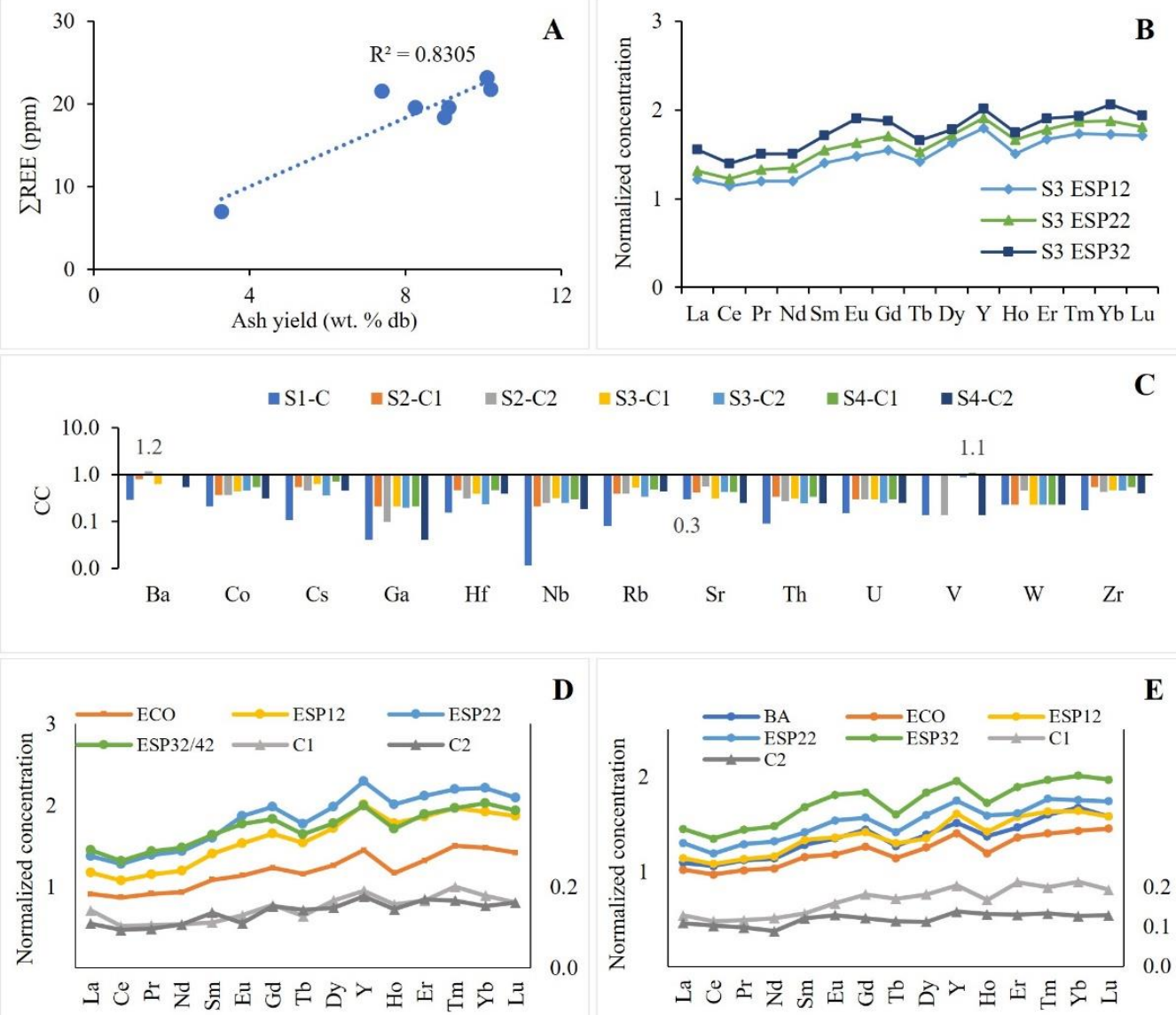

Figure 4. (A) Bivariate plot correlating ash yield (wt. \%) with $\sum$ REE; (B) REE concentrations from ESP ashes of S3, normalized to UCC [32]; (C) concentration coefficients (CC) of trace elements in the feed coals-normalized to average trace-element concentrations in world hard coals [31]; comparison of REE concentrations normalized to UCC from feed coals and the respective ashes from the campaigns: (D) S2, and (E) S4.

With regard to the REE enrichment patterns after the normalization to UCC: four coals present $\mathrm{H}$-type enrichment $\left(\mathrm{La}_{\mathrm{N}} / \mathrm{Lu}_{\mathrm{N}}<1\right)$, namely, $\mathrm{C}_{1}$ and $\mathrm{C}_{2}$ from $\mathrm{S} 2$, and $\mathrm{C}_{1}$ and $\mathrm{C}_{2}$ from S4; two present L-type enrichment $\left(\mathrm{La}_{\mathrm{N}} / \mathrm{Lu}_{\mathrm{N}}>1\right)$, namely, S1-C and S3-C 1 ; and one presents M-type enrichment $\left(\mathrm{La}_{\mathrm{N}} / \mathrm{Sm}_{\mathrm{N}}<1, \mathrm{Gd}_{\mathrm{N}} / \mathrm{Lu}_{\mathrm{N}}>1\right)$, without Eu anomaly, namely, S3-C 2 (Table S1; $[18,32])$. All coals present negative $\mathrm{Ce}$ anomalies and positive $\mathrm{Gd}$ anomalies. The samples, $S 2-\mathrm{C}_{2}$ and $\mathrm{S} 1-\mathrm{C}$, can be differentiated from the others through the negative anomalies in $\mathrm{Eu}$ and $\mathrm{Y}$, respectively (Table S1).

The remaining trace elements analyzed occur in the following order of average concentrations: $\mathrm{Ba}>\mathrm{Sr}>\mathrm{V}>\mathrm{Zr}>\mathrm{Rb}>\mathrm{Co}>\mathrm{Nb}>\mathrm{Ga}>\mathrm{Th}>\mathrm{U}>\mathrm{Cs}>\mathrm{Hf}>\mathrm{W}$ (Table S1). Be, Sn, and Ta were below the detection limits. Most of these trace elements were depleted, relative to the world hard coals, with low concentration coefficient $(C C<0.5)[31,105]$ (Figure 4C). As was verified for the REEs, the feed coal from S1 has the lowest concentrations for all the trace elements analyzed.

The coal combustion ashes present higher concentrations than their respective feed coals, of all the trace elements analyzed (Table S2). The REE contents in the coal ashes are in the range of 159.9-266.6 ppm, 8 to 30 times more than the feed coals, with a global 
CV of $13.10 \%$ (Table S2). Still, the average REE content, $211 \mathrm{ppm}$, is low compared to the averages reported for coal ashes from China (473 ppm), the United States (460 ppm), Europe (279 ppm), and others (298 ppm) [41], as well as the references therein. The ashes present H-type enrichment $\left(\mathrm{La}_{\mathrm{N}} / \mathrm{Lu}_{\mathrm{N}}<1\right)$, positive anomalies of $\mathrm{Y}, \mathrm{Eu}$, and $\mathrm{Gd}$, and negative anomalies of $\mathrm{Ce}$ (Table S2). The similarities to the feed coal patterns and anomalies suggest that the REEs have not been significantly differentiated among the ashes (Figure 4D,E).

The predominance of other trace elements in the ashes, considering their average concentrations, is similar to that found in feed coals: $\mathrm{Ba}>\mathrm{Sr}>\mathrm{V}>\mathrm{Zr}>\mathrm{Rb}>\mathrm{Ga}>\mathrm{Co}>\mathrm{Nb}$ $>\mathrm{Th}>\mathrm{Cs}>\mathrm{Sn}>\mathrm{U}>\mathrm{Hf}>\mathrm{W}>\mathrm{Be}>\mathrm{Ta}$ (Table S2). The elements, Nb, Cs Ga, Rb, V, and Th, presented the highest enrichments in relation to the respective feed coals, by 21 to 92 times, on average. Compared to the average values defined by Ketris and Yudovich [31] for coal ashes, most of the elements were found depleted or in normal concentrations $(C C<2)$, except for V, which was slightly enriched $(2<\mathrm{CC}<5)$ in the ESP fly ashes, from the last rows from S2-S4. However, the Ga concentrations in the back ESP rows are near or above the cutoff of $50 \mathrm{ppm}$ for its coproduction with $\mathrm{Al}$ [11]. Gallium shows relative enrichments (RE), up to 6 in the back rows, and about 1 in BA (Table S3), suggesting its volatilization during combustion and further condensation triggered by the temperature decrease in the ESP. The back rows capture small amounts of fly ash. However, a selective collection could be considered for the extraction of this critical raw material [5].

The average REE concentrations of the sampling campaigns decrease as follows: S3, $226.76 \mathrm{ppm}>\mathrm{S} 2,225.19 \mathrm{ppm}>\mathrm{S} 4,214.81 \mathrm{ppm}>\mathrm{S} 1,190.65 \mathrm{ppm}$ (Table 8). This shows the importance of the REE content in the parent coal, since the coal ashes generated from $\mathrm{S} 1$ resulted from the feed coal containing the lowest amount of REEs (Table S1). Campaign S2 presented the greatest variation in the REE content among the ashes (88.67 ppm), corresponding to a CV of $14.25 \%$ (Table 8 ).

Table 8. Descriptive statistics regarding REE contents ( $\left.\sum R E E\right)$ of coal ashes by sampling campaign.

\begin{tabular}{llccccc}
\hline & & Minimum & Maximum & Range & Average & Coefficient of Variation (CV) \\
\cline { 3 - 6 } & \multicolumn{5}{c}{ ppm } \\
\hline S1 & Global & 159.94 & 207.80 & 47.86 & 190.65 & \% \\
& ESP 12-42 & 191.14 & 194.53 & 3.39 & 193.00 & 7.19 \\
& ESP 15-45 & 178.19 & 206.85 & 28.66 & 193.14 & 0.73 \\
S2 & Global & 169.79 & 258.46 & 88.67 & 225.19 & 0.86 \\
& ESP 12-42 & 220.24 & 258.46 & 38.22 & 244.84 & 14.25 \\
S3 & Global & 197.48 & 266.07 & 68.59 & 226.76 & 7.12 \\
& ESP 12-32 & 219.08 & 266.07 & 46.99 & 240.87 & 10.33 \\
S4 & Global & 182.33 & 257.14 & 74.81 & 214.81 & 8.03 \\
& ESP 12-32 & 205.09 & 257.14 & 52.05 & 230.06 & 11.02 \\
\hline ESP: electrostatic precipitator & & & & 8.10 \\
\hline
\end{tabular}

ESP: electrostatic precipitator.

The REE concentration is dependent on the sampling site and follows the order, ESP FA > BA > ECO FA (Table S2), which correlates positively with the production ratios of the materials within the power plant: 90\% ESP FA; $8 \%$ BA; and 2\% ECO FA. The smaller concentrations of REEs found in the BA, comparated to the ESP fly ash, is aligned with what has been reported in [4,42-44]. Except for $\mathrm{Zr}$, which is slightly more concentrated in the BA compared to the ECO and the ESP FA, the remaining trace elements present similar distributions to the REEs. Zirconium, as a REE, and Cs, Hf, Sr, and Th are classified as nonvolatile elements, and are expected to have an even distribution among the combustion products $(\mathrm{RE} \approx 1)$ [39]. Nevertheless, some variations are observed (Table S3) and may be related to aspects other than volatility, such as the mode of occurrence $[39,47,48,106]$.

Despite some variations, the REE concentrations and the respective relative enrichments, tend to increase towards the last row of ESP hoppers (Table S3). The highest variation of $\sum$ REE among the ESP fly ashes was found in S4, corresponding to $52.02 \mathrm{ppm}$, and a CV of $8.10 \%$ (Table 8 ). Except in the referred campaign, the LREE/HREE ratio also 
increases across the ESP, even though, in some cases, the maximum values can be found in the second row (S1 and S3, Table S2). Nevertheless, the comparison of the concentrations normalized to UCC [32] does not show significant REE partitioning (Figure 4B).

The increase in LREE/HREE ratio across the ESP rows was previously reported for a power plant burning high-S coals from western Kentucky [13]; however, most of the published data describe a decrease in the LREE/HREE ratio (e.g., $[47,107])$, as in S4 (Table S2). Although these trends are not entirely understood but the following may play major roles [41,48]: (a) the vaporization-condensation of HREEs associated with OM; and (b) higher amounts of glass in the FA from the ESP back rows. The organic association of REEs is commonly linked with low-rank coals, but it can also be found in minor amounts in high-rank bituminous coals [79]. Considering the lack of REE fractionation, the slight variations observed in the current work are most likely due to the fly ash petrological differences (e.g., amount of glass).

\subsubsection{Geochemical Associations}

The modes of occurrence of the REEs in the feed coals and the respective ashes were initially investigated using statistical analysis (hierarchical cluster analysis and Pearson's correlation coefficients), which can provide information concerning organic and inorganic affinities and the potential relations among elements [108-110]. Oxides and elements from feed coals with more than one value below the detection limit (bdl) were excluded to avoid skewness in the results. The bdl values considered for the analysis were replaced by bdl/ 2 .

The associations between the oxides and trace elements in the feed coals are broadly indicated by the dendrogram in Figure 5, the correlation coefficients (CC) are presented in Table S4, and two major groups of elements are distinguished (Figure 5).

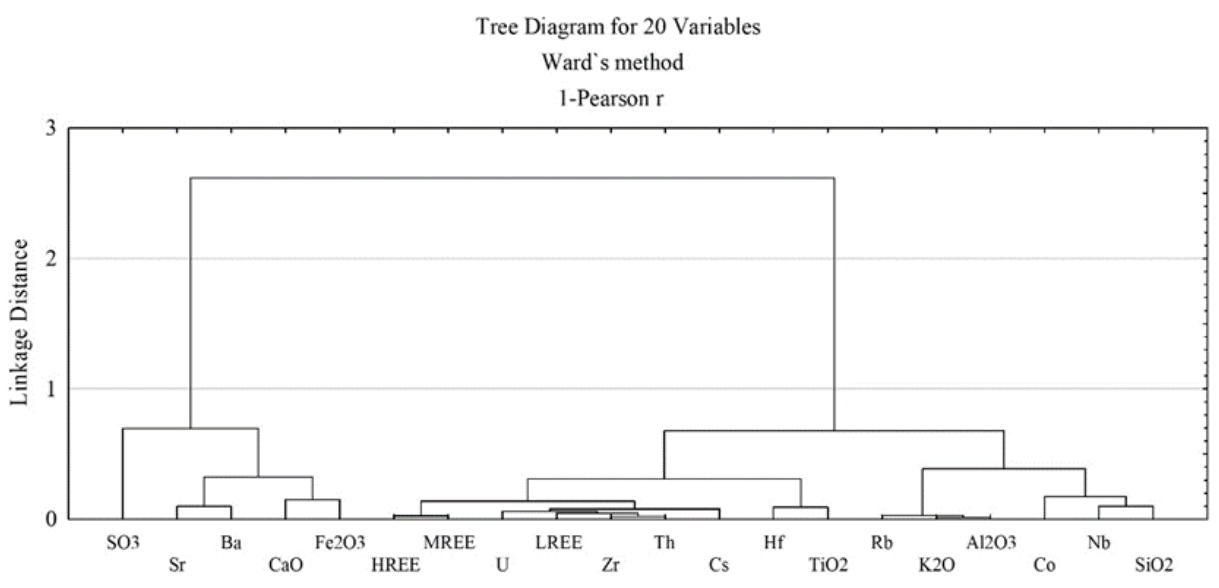

Figure 5. Dendrogram developed from cluster analysis on the geochemical data from feed coals (cluster method, Ward's method; interval, Pearson's correlation values).

The first group includes $\mathrm{SO}_{3}, \mathrm{Sr}, \mathrm{Ba}, \mathrm{CaO}$, and $\mathrm{Fe}_{2} \mathrm{O}_{3}$ (Figure 5). These elements do not show significant positive correlations with ash $(\mathrm{r}<0.64), \mathrm{SiO}_{2}(\mathrm{r}<0.51)$ or $\mathrm{Al}_{2} \mathrm{O}_{3}(\mathrm{r}<0.53)$, and, except for $\mathrm{SO}_{3}$ and $\mathrm{Sr}$, they present a strong negative correlation with carbon: $\mathrm{r}>-0.81$ (Table S4). These correlations are most likely related to the sulfate and sulfide minerals found in feed coals, such as gypsum and pyrite (Table 3).

The second group consists of REEs and the remaining elements. Except for $\mathrm{Hf}$, they show a strong positive relation to ash $(\mathrm{r}>0.80, \rho<0.05)$. Apart from $\mathrm{TiO}_{2}, \mathrm{~K}_{2} \mathrm{O}$, and $\mathrm{Hf}$, the elements in this second group also show a significant negative correlation with carbon $(r<-0.76, \rho<0.05)$, suggesting an inorganic association, which is in line with several studies showing REEs primarily associated with minerals in coals (e.g., $[18,79,111])$. The REEs appear to be closely associated with $U(r>0.91)$, Th $(r>0.94)$, Cs $(r>0.90)$, and $\mathrm{Zr}(\mathrm{r}>0.95)$, and all the elements are significantly correlated with each other, suggesting a common source (Table S4). Since $\mathrm{Zr}$ is also found to be positively correlated with 
$\mathrm{SiO}_{2}(\mathrm{r}>0.78)$, these correlations can represent the occurrence of zircon, where lithophile elements, such as REE, $\mathrm{U}$ and Th, are commonly found incorporated [112].

The REE-bearing phases typically occur in volumetric proportions below the XRD limits, and since SEM/EDS have been proven to be useful for their identification in coal and coal combustion ashes $[15,20,29,51,72,113]$, SEM/EDS investigations were conducted on the selected samples.

The examination of the selected feed coals via SEM/EDS enabled the identification of particles containing Ce-La-Nd (Figure 6A,C,E,F), Ce (Figure 6B), and Y-Dy-Gd (Figure 6D), with phosphorous as a major component. In some cases, the occurrence of $\mathrm{Ce}-\mathrm{La}-\mathrm{Nd}$ is associated with Th (Figure 6A,F). This corroborates the inorganic association suggested by the statistical analysis, with phosphates, most likely monazite and xenotime, as the REE carriers. The statistical correlation between REEs and P was not assessed because the $\mathrm{P}_{2} \mathrm{O}_{5}$ concentrations were below the detection limit (Table 3). This is in agreement with the study of Finkelman et al. [79], where sequential leaching experiments in nine samples of bituminous coals were performed and showed that REEs are mainly associated with phosphates (70\% LREE, 50\% HREE). No Sc-bearing particles were found, and no REEs were detected, outside the particles containing REEs. Zirconium-, Ti-, and Ba-bearing particles were found, but no REEs were detected in them. The particle sizes ranged from 0.31 to $3.47 \mu \mathrm{m}$, with an average of $1.45 \mu \mathrm{m}$ (measured in the longest section).

The REE-bearing phases were mainly found embedded in clays (Figure 6A,B,F), which corroborates the correlations found through statistical analysis. Few particles were found in the organic matter (Figure 6C) or embedded in quartz (Figure 6E). The spatial association of REE-bearing minerals with other minerals in coals (such as clays) can be an important factor with regard to their incorporation within the aluminosilicate glass of the resulting ashes [41].

The associations between oxides and trace elements in coal combustion ashes are indicated by the hierarchical clustering dendrogram in Figure 7, and the correlation coefficients are presented in Table S5 from the supporting information. Three main groups of elements are identified in the dendrogram. Group 1 includes the elements, $\mathrm{Zr}$ and $\mathrm{Hf}$, and the oxides, $\mathrm{SiO}_{2}$ and $\mathrm{Fe}_{2} \mathrm{O}_{3}$, which are positively correlated with ash $(\mathrm{r}>0.54, \rho<0.05)$, and negatively correlated with carbon $(r>-0.60, \rho<0.05)$, which suggests an inorganic occurrence (Table S5). In Group 2, the MREEs and HREEs are associated with $\mathrm{Co}, \mathrm{Sr}, \mathrm{Ba}, \mathrm{Be}, \mathrm{SO}_{3}, \mathrm{Na}_{2} \mathrm{O}$, and $\mathrm{CaO}$ (Figure 6). With the exception of $\mathrm{SO}_{3}$, these elements and oxides do not show significant correlations with either ash or carbon (Table S5), which points to mixed organic and inorganic associations. Nevertheless, significant correlations are not limited within the group, which suggests several modes of occurrence. All the REEs exhibited significant positive correlations with the oxides: $\mathrm{Al}_{2} \mathrm{O}_{3}(\mathrm{r}>0.66), \mathrm{P}_{2} \mathrm{O}_{5}(\mathrm{r}>0.56)$, and $\mathrm{TiO}_{2}(\mathrm{r}>0.67)$ (Table S5). The third group includes LREEs and the remaining trace elements, which were all significantly correlated with the major oxides: $\mathrm{Al}_{2} \mathrm{O}_{3}, \mathrm{~K}_{2} \mathrm{O}, \mathrm{TiO}_{2}$, and $\mathrm{P}_{2} \mathrm{O}_{5}$ (Table S5). As with MREEs and HREEs, the LREEs do not present significant correlations with ash or with carbon, suggesting that REEs can occur in organic and inorganic associations.

The relationship with the major oxides suggests the possible occurrence of REEs in sulfates, phosphates, and aluminosilicate glass. The existence of nano-sized REE-bearing particles in carbon was reported in fly ashes derived from bituminous coals $[20,114,115]$. Even so, most of the studies show that the REEs in coal combustion ashes are mainly associated with aluminosilicate glass (e.g., $[9,15,24,27,96,107,116-119])$. This association could be the result of the incorporation of the REE-bearing phases, or, less probably, to the REE diffusion into the glass phase [41].

The results of the REE-bearing phase tracking via SEM/EDS in the bulk ash particulate blocks from S1 are summarized in Table 9. A total of 17 REE-bearing particles were identified in nine ash samples, and the numbers of particles found per polished block ranged from 1 to 5 . In the BA and the FA from the economizer and silo, three REE-bearing particles were identified, one in each sample. In the FA from the ESP, a total of 14 particles were counted, 9 in the samples from rows $12-32 / 42$, and 5 in the samples from the opposite 
side. The particle sizes ranged from 0.38 to $8.62 \mu \mathrm{m}$, with a corresponding average size of $3.35 \mu \mathrm{m}$ (Table 9).
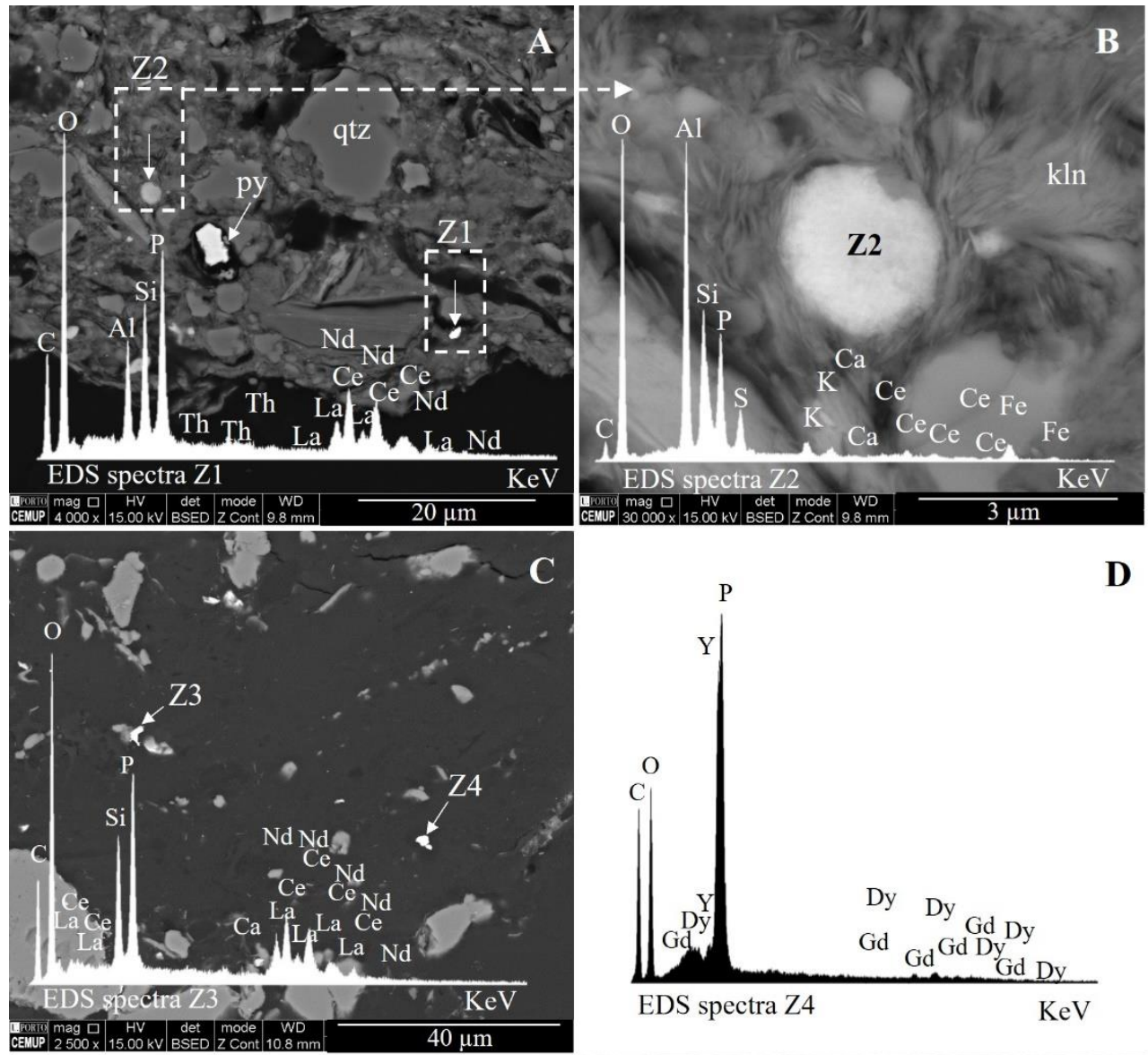

D
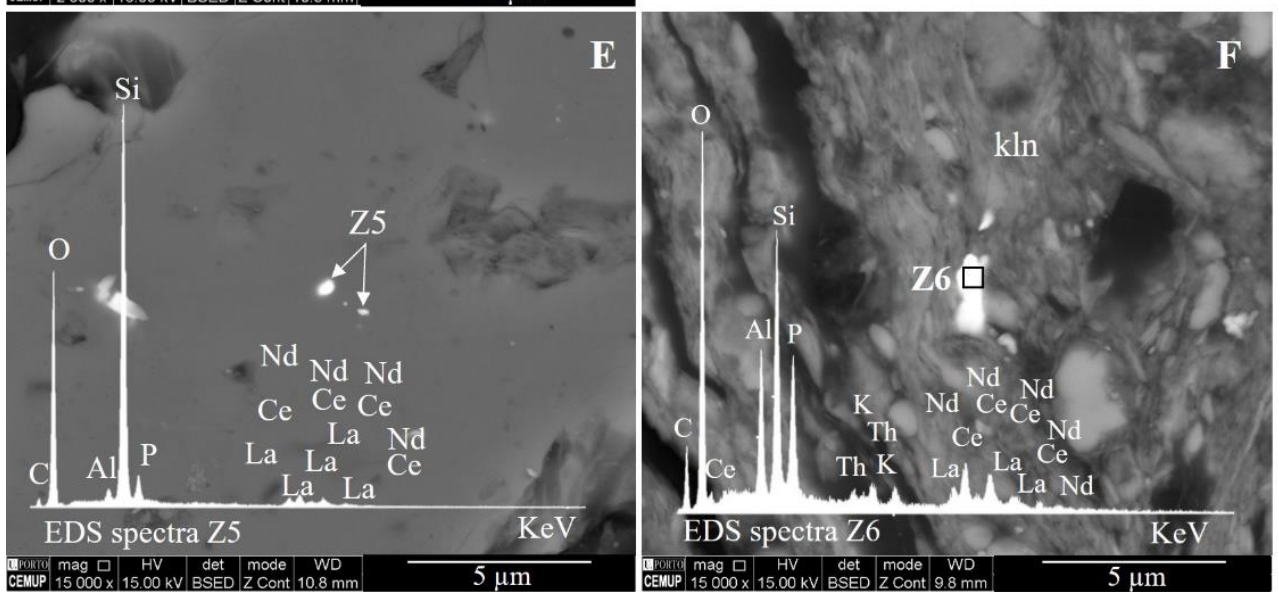

Figure 6. Examples of REE-bearing particles found on feed coals via SEM/EDS experiments: (A) general view of coal matrix with particles bearing Ce-La-Nd, with $\mathrm{P}$ as major element intermixed with clays, dashed square, Z1, and EDS spectrum (Z1, ×4000); (B) magnification of dashed square, Z2, in " $\mathrm{A}$ ", and EDS spectrum, Z2, illustrating rounded Ce-bearing particle intermixed with kaolinite $(\mathrm{K} \ln )(\times 20,000)$; (C,D) REE-bearing phosphates hosted in organic matter $(\times 2500)$; (E) particle bearing Ce-La-Nd, with $\mathrm{P}$ as major element in quartz (qtz); and (F) particle-bearing Ce-La-Nd and Th, with $\mathrm{P}$ as major element intermixed with clays $(\times 15,000)$; py: pyrite. 


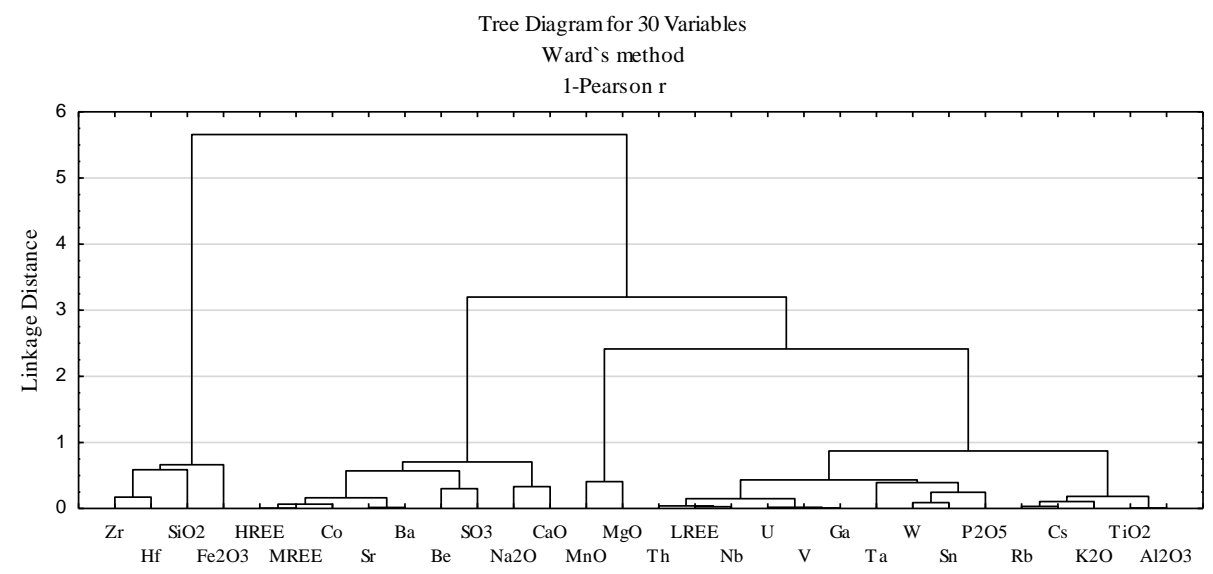

Figure 7. Dendrogram from cluster analysis on the geochemical data from bulk ashes (cluster method, Ward's method; interval, Pearson's correlation values).

Table 9. Descriptions of the REE-bearing grains found in the ash particulate blocks by SEM/EDS.

\begin{tabular}{|c|c|c|c|c|c|}
\hline Sample & $\begin{array}{l}\text { Grains } \\
\text { Counted }\end{array}$ & $\begin{array}{l}\text { Size } \\
(\mu \mathrm{m})\end{array}$ & Major Element (s) & REE Detected & Description \\
\hline S1-BA & 1 & a 0.76 & $\mathrm{P}$ & Ce-La-Nd & $\begin{array}{l}\text { Particles embedded in glass }(\mathrm{Si}-\mathrm{Al}< \\
\mathrm{Mg}-\mathrm{Fe}<\mathrm{K}-\mathrm{Ti}-\mathrm{Ca}-\mathrm{Na})\end{array}$ \\
\hline S1-ECO & 1 & 3.07 & $\mathrm{P}$ & Ce-La-Nd & $\begin{array}{l}\text { Spherical particle embedded in glass } \\
(\mathrm{Si}-\mathrm{Al}<\mathrm{Na}-\mathrm{K}<\mathrm{Fe}-\mathrm{Mg}-\mathrm{Ca})\end{array}$ \\
\hline & & 3.20 & $\mathrm{Al}-\mathrm{Si}$ & Ce-La-Nd & Spherical particle retained on char pore \\
\hline S1-ESP 12 & 2 & 1.55 & Si-Al & $\mathrm{Y}$ & Spherical discrete particle \\
\hline S1-ESP 15 & 1 & 3.10 & $\mathrm{P}$ & Y-Tb-Dy & Rounded discrete particle \\
\hline \multirow{3}{*}{ S1-ESP 22} & \multirow{3}{*}{2} & a 0.38 & $\mathrm{Zr}$ & $\mathrm{Y}$ & Particles embedded in Si-Al glass \\
\hline & & 1.54 & $\mathrm{P}$ & Ce-La-Nd & Spherical discrete particle \\
\hline & & 3.39 & $\mathrm{P}$ & Ce-La-Nd & Angular discrete particle \\
\hline \multirow[t]{4}{*}{ S1-ESP 25} & \multirow[t]{4}{*}{3} & 2.14 & $\mathrm{Al}-\mathrm{Si}$ & Ce-La-Nd & Spherical discrete particle \\
\hline & & 2.48 & $\mathrm{Al}-\mathrm{Si}$ & Ce-La-Nd & Spherical discrete particle \\
\hline & & 2.64 & $\mathrm{P}$ & Ce-La & Angular discrete particle \\
\hline & & 4.22 & Si-Al & Y-Dy & Spherical discrete particle \\
\hline \multirow[t]{3}{*}{ S1-ESP 32/42 } & \multirow[t]{3}{*}{5} & 5.01 & Si-Al & Ce-La-Nd & Spherical particle retained on char pore \\
\hline & & 8.62 & $\mathrm{P}$ & Y-Dy-Er-Gd-Yb & Spherical discrete particle \\
\hline & & 5.92 & $\mathrm{P}$ & Ce-La-Nd & Angular discrete particle \\
\hline S1-ESP 35/45 & 1 & 6.13 & Al-Si & Ce-La-Nd & Spherical discrete particle \\
\hline Silo & 1 & 2.89 & $\mathrm{P}$ & Ce-La-Nd & Spherical discrete particle \\
\hline Total & 17 & $\begin{array}{l}\text { Mean: } \\
3.35\end{array}$ & & & \\
\hline
\end{tabular}

${ }^{\text {a }}$ Average of 10 particles measured; BA: bottom ash; ECO: economizer; FA: fly ash.

The particles included Ce-La (one count), Ce-La-Nd (eleven counts), Y (two counts), Y-Dy (one count), Y-Dy-Tb (one count), and Y-Dy-Er-Gd-Yb (one count), with phosphorous or aluminosilicate glass as major components (Table 9). Most of the REE-bearing phases were found to occur as discrete particles, with spherical/rounded or angular shapes (Figure 8A,B), with a few trapped on char pores (Figure 8D), and a small number were found embedded in aluminosilicate glass (Figure 8C,E,F). The REE-bearing phases identified in the feed coals, such as monazite and xenotime, appear to persist in the combustion ashes. In some discrete particles with $\mathrm{P}$ as a major component, $\mathrm{Si}$ and $\mathrm{Al}$ were also detected, but further analysis would be needed in order to assess the nature of these associations. The existence of discrete particles trapped on char can have an influence on the statistical analysis, and it might indicate an organic correlation that does not exist. 

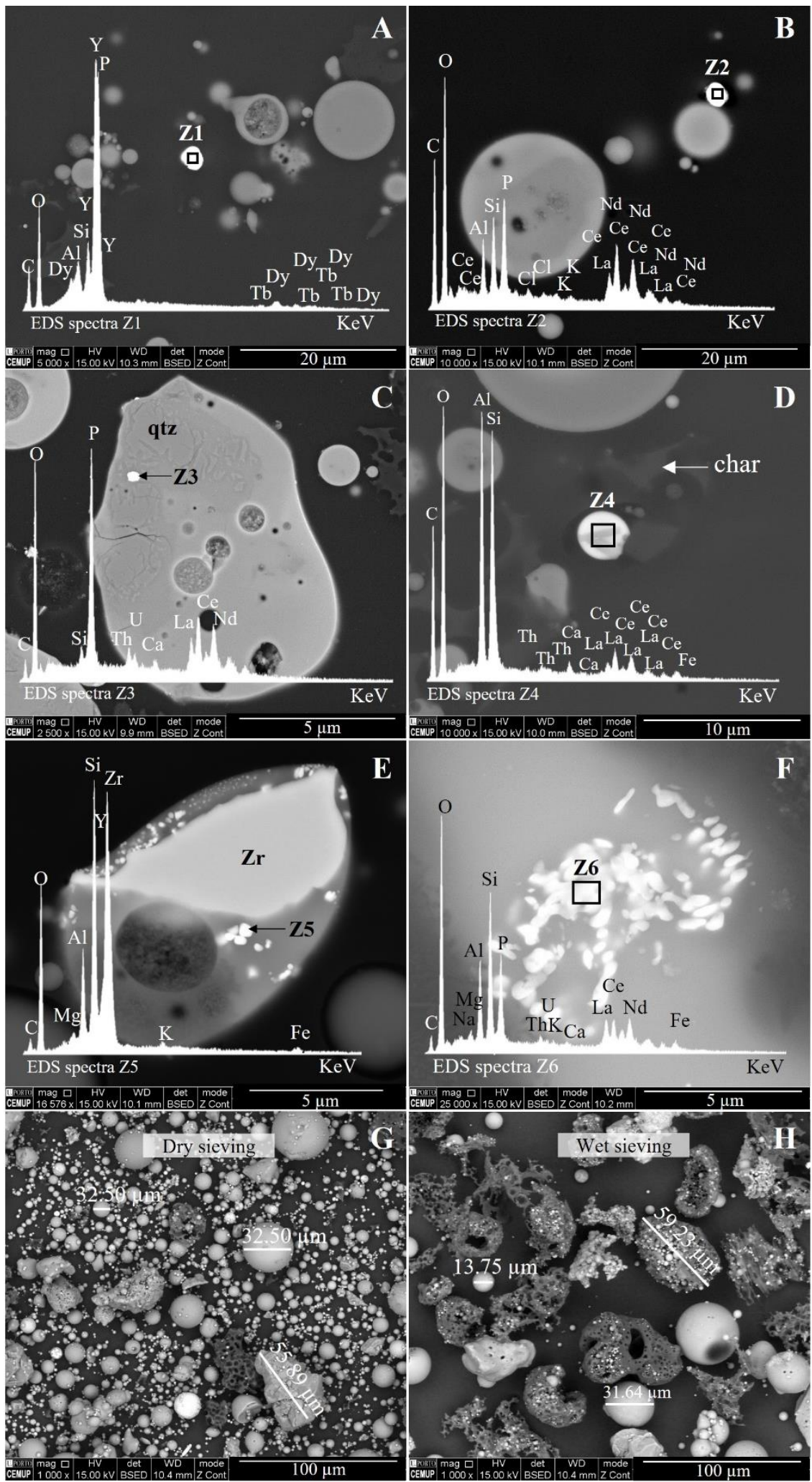

Figure 8. Observations under SEM/EDS (BSE mode): (A) discrete Y-Dy-Tb-bearing particle with $\mathrm{P}$ as major component $(\times 5000)$; $(\mathbf{B})$ discrete rounded particle bearing Ce-La-Nd, with $\mathrm{P}$ as major component $(\times 10,000) ;(C)$ rounded particle bearing Ce-La-Nd, with $\mathrm{P}$ as major component, embedded in Al-Si glass beside quartz, qtz $(\times 2500)$; (D) spherical Ce-La-Nd-bearing particle trapped in char pore $(\times 10,000)$; (E) Zr-phases incorporated in aluminosilicate glass; (F) Particles with Ce-La-Nd and Th-U embedded within an Al-Si-Ca glass that also contains Ce-La-Nd-Th-U; size-fraction: $42-25 \mu \mathrm{m}$ from S1-ESP12 sample, before $(\mathbf{G})$ and after $(\mathbf{H})$ wet sieving (BSE mode, $\times 1000$ ). 
No carrier phases for Sc were found, and REEs were not detected in the Ba- and Ti-bearing particles identified. Instead, Zr-bearing particles containing Y (i.e., zircon; Figure $8 \mathrm{E}$ ) were found embedded in an aluminosilicate glass and were adjacent to a $\mathrm{Zr}$ bearing phase without traceable REEs (Figure $8 \mathrm{E}$ ). The particles seem to have resulted from the $\mathrm{Zr}$-bearing phase breakdown with the partitioning of the $\mathrm{Y}$ to the melt. Y-bearing zircons have been previously detected in fly ash samples by SEM/EDS and TEM [20,107].

Furthermore, Liu et al. [107] also observed a Zr-phase exhibiting melting features similar to those observed in this research. Zircon is often considered to be stable at high temperatures $\left(1690^{\circ} \mathrm{C}\right.$; [120]) and, thus, to be resistant to the combustion process; however, its alteration is well known in natural igneous systems [121]. Several particles displaying similar features were identified, but no REEs were detected in them.

In the bottom ash sample, P-bearing particles with $\mathrm{Ca}$ and Ce-La-Nd are visually identical to the Zr-bearing particles with Y (Figure 8F). However, in this case, REEs were also detected in the aluminosilicate glass (brighter area), which appear to be homogeneous, and the facet observed could have resulted from the REE diffusion into the Si-Al glass. Nevertheless, without further detailed analysis, the occurrence of REE-bearing nanoparticles or REE-enriched domains at the nanoscale must be considered (e.g., [20]). Liu et al. [107] studied the decomposition of pure typical REE carriers in coals and verified the melting characteristics on REE phosphates. Apatite, which is an important REE carrier in coal, can decompose to other phases at temperatures above $1000^{\circ} \mathrm{C}$ [41].

\subsubsection{Particle Size and Magnetic Fractions}

Several studies have shown that greater REE concentrations are usually found within finer-particle-sized and nonmagnetic fractions, particularly in fly ashes $[16,21,22,49])$. Moreover, the removal of the Fe-rich fraction before the REE extraction process is important since iron oxides can compete with REE during the hydrometallurgical process (acid leaching) [122]. With consideration to this, the selected ash samples were sieved and magnetically separated, and the resulting fractions were analyzed via ICP-MS to assess the REE distribution.

The ashes from S1 and S4 were used for sieving since all the sampling locations were included (BA, ECO, and ESP FA). The fractions $>150 \mu \mathrm{m}$ from the ESP fly ashes represented $<2 \mathrm{wt} . \%$ of the bulk ash, so they were added to the 150-75 $\mu \mathrm{m}$ fractions, and this was labelled as $>75 \mu \mathrm{m}$. A substantial retention of the micrometric particles was spotted on the 45-25 $\mu \mathrm{m}$ fractions via SEM/EDS (Figure 8G). Even when using low amounts of sample, the high adhesion forces in the finer particles can cause agglomeration and can lead to its retention [123-125]. To assess the effect of this on the REE distribution, wet sieving trials were performed on $<45-\mu \mathrm{m}$ fractions from the first ESP row samples, and the fractions were analyzed. Wet sieving removed, on average, $20 \mathrm{wt} \%$ of the fraction $(45-25 \mu \mathrm{m})$, visibly reducing the amount of the micrometric glass particles retained (Figure $8 \mathrm{H}$ ).

Magnetic separation was performed on six ash samples, BA, ECO, and ESP-12 from S1 and S4. Wet magnetic separation was used to reduce the possibility of particle agglomeration.

The REE enrichment was characterized using the same parameters as Lin et al. [22]: the enrichment factor (EF), which is calculated by dividing the REE concentration in the fraction by that in the feed, as given by Equation (4), and the REE recovery, defined by the ratio of the amount of total REE in each fraction to the amount of total REE in the feed, as in Equation (5). To reduce the influence of sample heterogeneity, the REE concentration in the feed was calculated by mass balance [22]:

$$
\begin{gathered}
E F_{i}=\frac{R E E_{i}}{\sum_{i=1}^{n}\left(R E E_{i} W_{i}\right)} \\
R_{i}(\%)=\frac{R E E_{i} W_{i}}{\sum_{i=1}^{n}\left(R E E_{i} W_{i}\right)} \times 100
\end{gathered}
$$


where $R E E_{i}$ is the total $R E E$ concentration of the fraction; $W_{i}$ is the weight percentage of the fraction; and $n$ is the total number of fractions.

The results regarding the yield (wt. \%), trace elements (ppm), REE anomalies, EF, and recovery of the size and magnetic fractions, are summarized in Table S6.

The REE distribution across the size-fractions differs according to the type of material. In the BA size-fractions, the REE concentrations vary by, on average, $29 \mathrm{ppm}$ (184.3-213.5 ppm avg.), and the coarser fractions generally have slightly higher concentrations (Table S5). The enrichment factor (EF) varies between 0.92 and 1.10, while the recovery can reach up 39.4\%. The fractions greater than $1 \mathrm{~mm}$ (comprising $>50 \mathrm{wt} \%$ of bulk ash) present recoveries of twice as much of the remaining size-fractions (Figure 9 ). The coarse nature of the particles facilitates their separation and represents a recovery higher than $60 \%$ of the REEs present in the BA.

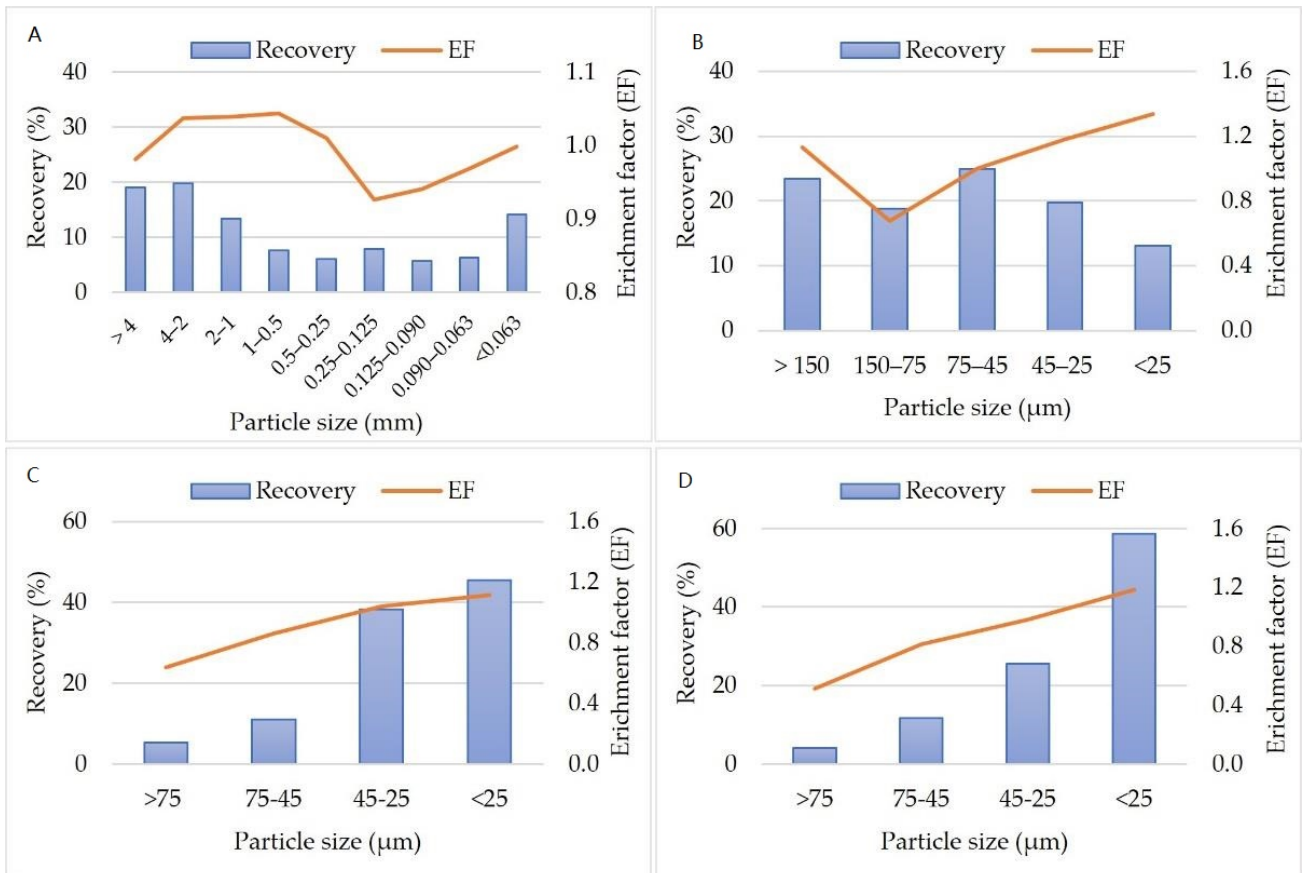

Figure 9. REE enrichment factors and recoveries (\%) in the size-fractions obtained by dry sieving: (A) BA from S1; (B) ECO fly ash from S1; (C,D) ESP fly ash from S1 and S4, respectively.

In the FA samples, the REE content is higher in the finer fractions $(<25 \mu \mathrm{m})$, which is in agreement with what has been reported in $[16,21,23,45]$, but some differences are verified between the ECO and ESP. In the ECO FA, the REE content decreases by $20-40 \%$ (42-75 ppm) between the fractions $>150 \mu \mathrm{m}$ and $150-75 \mu \mathrm{m}$, before progressively increasing till fractions $<25 \mu \mathrm{m}$ (Table S5).

The recovery on the ECO size-fractions varies within a range of approx. 10\% (13.85-25.79\% avg.) (Figure 9). Still, the EF can reach up to $1.32-1.34$ in the $<25-\mu \mathrm{m}$ fraction, which is higher than the EF found for the same size-fraction from the ESP FA (1.05-1.24). However, as is shown in Figure 9, the REE recoveries on fractions $<25 \mu \mathrm{m}$ in the ESP FA are above $40 \%$, while, in the ECO FA, the recoveries are below 17\%. The wet sieving led to a decrease in the EF on fractions $<25 \mu \mathrm{m}$, while the recoveries increased to the range of $78.3-86.2 \%$. As stated by Willis [126], the grade and the recovery inversely correlate, which means that higher recoveries imply more impurities on the product, and, consequently, a lower grade (and EF). Ultimately, both parameters should be kept as high as possible during the beneficiation process.

As is observed in this study, and as has been previously reported, the LREE/HREE ratio in the fly ashes from the ESP tends to decrease with the decreasing particle size [16,17,21-23,127], although, in some cases, there is a slight increase between the fractions $>75 \mu \mathrm{m}$ and $75-45 \mu \mathrm{m}$, before decreasing towards $<25-\mu \mathrm{m}$ fractions (Table S6). In comparison, the REE distributions 
on the ECO fly ash samples are similar, but their LREE/HREE ratios show the opposite trend (Table S6). The examination of the REE normalized patterns vs. the particle size (Figure 10) shows no significant fractionation between the size-fractions, suggesting that the differences found on the LREE/HREE ratio may result from differences in the fly ash petrology, e.g., the amount of glass [41]. Despite some variations, the remaining trace elements analyzed show distributions similar to those described for the REEs (Table S6).
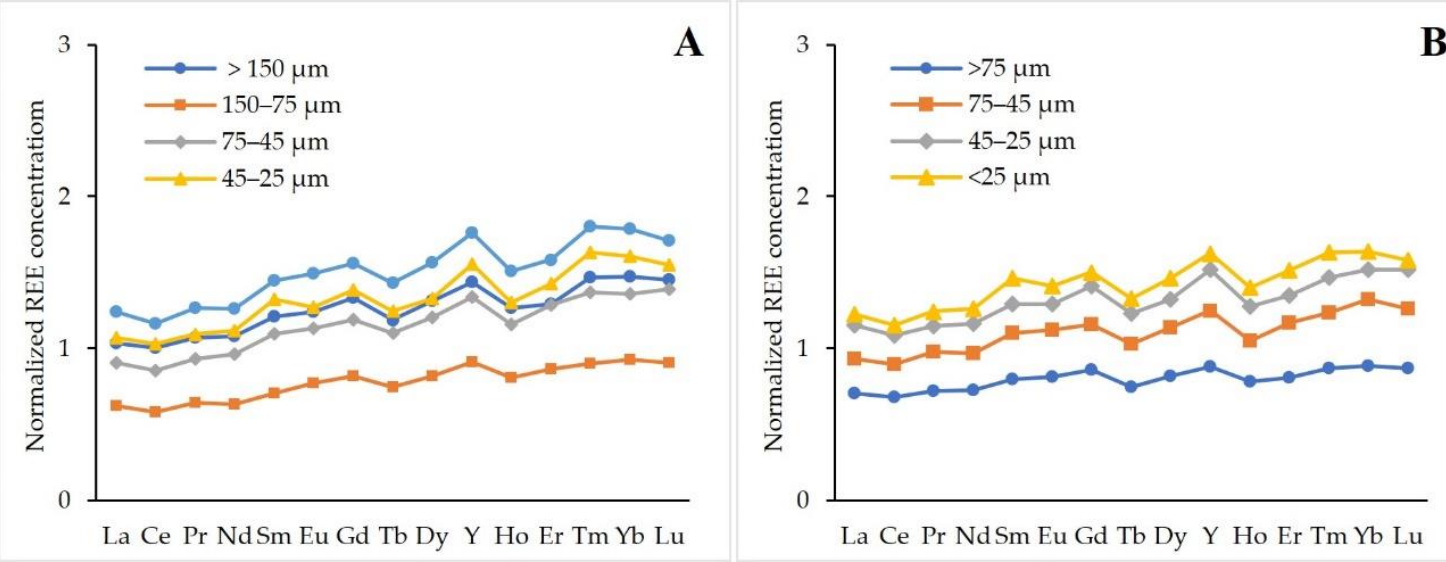

\section{B}

Figure 10. Examples of normalized REE distribution patterns (relative to UCC, [32]) of fly ash size-fractions from S1: (A) economizer; and (B) ESP, hopper 12.

The nonmagnetic fractions of the ESP fly ashes contained up to 53.96 ppm more REEs than the respective magnetic fractions, with an EF ranging between 1.06 and 1.10 (Table S7). The REE concentration changes slightly between the magnetic and nonmagnetic fractions of the BA and ECO fly ash. Yet, minor enrichments in the magnetic fractions are noted for some REEs: (a) S1-ECO, Sm-Eu and Yb; (b) S1-BA, Sm-Eu, Tb-Y, and Yb; and (c) S4-ECO, Gd-Y and Tm (Table S7). The enrichment of REEs, such as Pr, Gd, and Tb, have been previously noted in magnetic fractions from fly ashes, despite their lower REE contents $[15,128]$.

All the magnetic fractions show slightly higher percentages of critical REEs, up to $2.2 \%$, but the REE recoveries are significantly lower than in nonmagnetic fractions (Table S7). Additionally, they contain slightly higher concentrations of other critical elements, such as $\mathrm{Co}, \mathrm{Ga}, \mathrm{V}$, and $\mathrm{W}$, compared to the nonmagnetic fractions (Table S7). The removal of Fe-rich fractions, in addition to being beneficial downstream for REE extraction, could result in a value-added product.

Overall, the fractions analyzed (size, magnetic, and nonmagnetic) show an enrichment pattern of the $\mathrm{H}$-type $\left(\mathrm{La}_{\mathrm{N}} / \mathrm{Lu}_{\mathrm{N}}<1\right)$, weak positive anomalies of Eu, positive anomalies for $\mathrm{Y}$ and Gd, and negative anomalies for Ce (Tables S6 and S7), resembling the results found for the bulk ashes.

A single trial, combining magnetic separation and dry sieving (cut at $25 \mu \mathrm{m}$ ), was performed on S1-ESP12. The final product corresponded to $42.8 \mathrm{wt} \%$, and presented an REE content of $240.83 \mathrm{ppm}$, an enrichment factor of 1.25 , and a recovery of $53.3 \%$. This represented an increase of almost $50 \mathrm{ppm}$ in the REEs, relative to the raw sample.

\subsubsection{Preliminary Evaluation of REE Potential}

The REE potential of the coal combustion ashes and the respective fractions (size, magnetic, and nonmagnetic) analyzed under this research was assessed following the method established by Seredin [50] and Seredin and Dai [18]. This method is based on plotting the percentage of the critical REEs $(\mathrm{Y}+\mathrm{Nd}+\mathrm{Eu}+\mathrm{Tb}+\mathrm{Dy}+\mathrm{Er})$ in the total REEs, identified as the $R E Y_{\text {def, rel }} \%$, versus the ratio of critical/excessive REEs $((\mathrm{Nd}+\mathrm{Eu}+\mathrm{Tb}$ $\left.\left.+\mathrm{Dy}+\mathrm{Er}+\mathrm{Y}) / \sum \mathrm{REE}\right) /\left((\mathrm{Ce}+\mathrm{Ho}+\mathrm{Tm}+\mathrm{Yb}+\mathrm{Lu}) / \sum \mathrm{REE}\right)\right)$, identified as the "outlook coefficient" $\left(\mathrm{C}_{\text {outl }}\right)$, and it essentially evaluates the quality of the ore. Dai et al. [51] updated 
the method by adding $1000 \mathrm{ppm}$ of REO (rare earth elements as oxides) as the minimum content for an economic extraction.

The bulk ashes exhibit $\mathrm{C}_{\text {outl }}$ in the range of 0.95-1.18, and a $R E Y_{\text {def, rel }} \%$ between 35.19 and $40.01 \%$, placing them in the category of a "promising" raw material (Table S6; Figure 11A). However, considering the updated version of Dai et al. [51], the bulk ashes are not considered to be economical because the REO contents are below $1000 \mathrm{ppm}$ (Figure 11B). The size, magnetic, and nonmagnetic fractions present similar $\mathrm{C}_{\text {outl }}$ and $\mathrm{REY}_{\mathrm{def}}$, rel $\%$ to the bulk ashes: $0.93-1.13$ and $38.96 \%$, respectively (Tables S6 and S7; Figure 11A). The REO content varies by a slightly wider range (111.35-327.49 ppm), reflecting the REE content variation described in Section 3.2.1., but it is still far below the cutoff (Figure 11B).
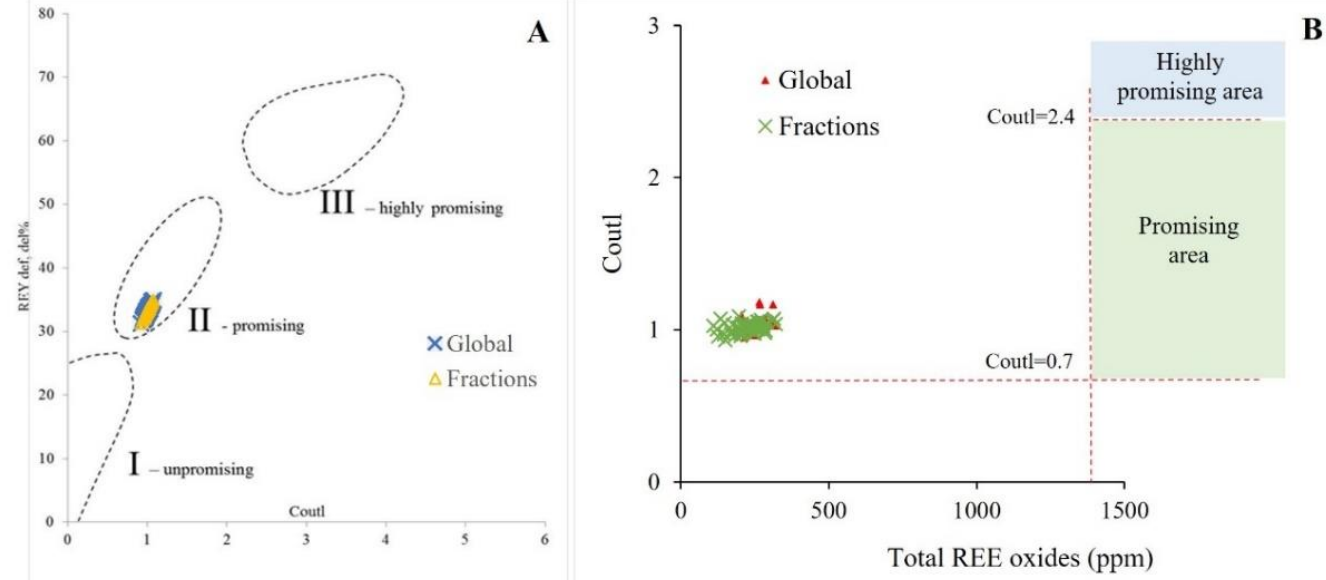

B

Figure 11. REE-potential evaluation of bulk ashes and respective fractions, according to (A) Seredin [50] and Seredin and Dai [18], REY def, rel vs. $C_{\text {outl }}$; and the (B) updated version from Dai et al. [51].

Even so, it is important to emphasize that the average percentage of critical REEs $\left(\mathrm{REY}_{\mathrm{def}, \mathrm{rel}} \%\right.$ ) found in either raw ashes or its fractions (37.13 and $36.68 \%$, respectively) is higher than in some conventional REE ores [41].

\section{Conclusions}

Samples of commercial Colombian coals and the respective combustion ashes, collected for over a year from the Pego power plant (Portugal), were characterized in order to assess the REE distribution and evaluate the potential of ashes as REE raw materials. Selected ash samples were fractionated and characterized to search for trends that could be used for further REE extraction.

Feed coals were predominantly medium D rank (high-volatile A bituminous coal) and vitrinite-rich, containing low-to-medium ash content and low sulfur content, and were mainly composed of quartz and kaolinite. The respective ashes are Class F, and they are mainly composed of aluminosilicate glass ( $>71.2$ vol. \%) and low $\mathrm{CaO}(<2.38 \mathrm{wt} . \%)$.

The coal sample REE concentrations ranged between 6.97 and $23.15 \mathrm{ppm}$, which is low compared to the world, U.S., and Chinese coals, which is most likely due to their beneficiation. The geochemical associations, corroborated by SEM/EDS, suggest an inorganic association, and Ce, La, Nd, Y, Dy, and Gd were found in $<10-\mu \mathrm{m}$ P-rich grains intermixed with clays.

The ash samples studied presented REE concentrations ranging from 159.9 to $266.6 \mathrm{ppm}$. The ESP FA present higher REE concentrations (217 ppm avg.) than the BA (195.45 ppm avg.) and ECO FA (170.69 ppm avg.), and generally increase towards the ESP back rows, along with the LREE/HREE ratio. During the SEM/EDS experiments, the REE were mainly detected in $<10-\mu \mathrm{m}$ discrete rounded particles, with $\mathrm{P}$ and $\mathrm{Al}-\mathrm{Si}$ as the major components. 
The REE content increases with the decreasing FA particle size. The EF in the ECO FA $<25-\mu \mathrm{m}$ fraction (1.33) was greater than the respective fraction in the ESP FA. However, the REE recovery is low in the former, while it can overcome $50 \%$ in the latter. With regard to the magnetic separation, the ESP FA nonmagnetic fraction is slightly enriched in REEs (>40 ppm), compared to the magnetic fraction, while no significant variations were found in the ECO and BA magnetically separated fractions. Meanwhile, the combination of magnetic separation, followed by the dry sieving of the ESP FA, increased the REE content by approx. $50 \mathrm{ppm}$, and recovered approx. 53\% of the REEs.

Overall, the normalized REE patterns and the individual element anomalies show no significant fractionation, either on the bulk ashes or the respective fractions; therefore, the variations found are most likely related to the variations in the fly ash petrology.

All the ash samples studied are promising REE raw materials, but their REO contents are far from the established cutoff of 1000 ppm [3,52]. Combining sieving and magnetic separation was insufficient to achieve the cutoff, but further trials may be conducted in the fractions proven to be more promising, by resorting to other concentration techniques (e.g., density separation) to try to increase the REE concentrations in the products. Nevertheless, with the increasing demand for REEs, the exploration of this type of low-grade secondary resource, requiring no mining and milling, may become profitable in the near future.

Supplementary Materials: The following supporting information can be downloaded at: https: / / www.mdpi.com/article/10.3390/min12020194/s1, Table S1: Trace elements (ppm), enrichment patterns and anomalies for individual REE for feed coals; Table S2: Trace elements (ppm), enrichment patterns, anomalies for individual REE for bulk coal combustion ashes; Table S3: Relative enrichments (RE) for trace elements according to Meij [39]; Table S4: Pearson correlation coefficients for feed coals. Statistically significant relations for $\rho>0.05$ in bold; Table S5: Pearson correlation coefficients for global ashes. Statistically significant relations for $\rho>0.05$ in bold; Table S6: Trace elements (ppm), enrichment patterns, anomalies for individual REE for coal combustion ashes size-fractions; Table S7: Trace elements (ppm), enrichment patterns, anomalies for individual REE for coal combustion ashes magnetic and non-magnetic fractions.

Author Contributions: Conceptualization, A.C.S., A.G. and B.V.; Data curation, A.C.S.; Formal analysis, all authors; Funding acquisition, B.V.; Investigation, all authors; Methodology, all authors; Supervision, A.G. and B.V. supervised A.C.S.; Writing - original draft, A.C.S.; Writing - review \& editing, all authors (A.C.S., A.G., B.V., D.F., A.F.). All authors have read and agreed to the published version of the manuscript.

Funding: This work is supported by national funding awarded by the FCT-Foundation for Science and Technology, I.P., and the EU under FEDER founds (POCI-01-0145-FEDER-007690), Program PT2020 (UIDB/04683/2020; UIDP/04683/2020), and the ERA-MIN Program project, CHARPHITE (FCT ref ERA-MIN/0005/2015). The author, A.C. Santos, benefited from a Ph.D. scholarship financed by the FCT (SFRH/BD/131713/2017 and COVID/BD/151941/2021).

Data Availability Statement: Not applicable.

Acknowledgments: The authors thank PEGOP_Energia Elétrica S.A. for the samples supplied and for the availability of the laboratory to carry out the proximate and ultimate analyses.

Conflicts of Interest: The authors declare no conflict of interest.

\section{References}

1. Connelly, N.G.; Damhus, T.; Hartshorn, R.M.; Hutton, A.T. Nomenclature of Inorganic Chemistry; Royal Society of Chemistry (Great Britain); International Union of Pure and Applied Chemistry; Royal Society of Chemistry: London, UK, 2005; ISBN 978-0-85404-438-2.

2. Haque, N.; Hughes, A.; Lim, S.; Vernon, C. Rare Earth Elements: Overview of Mining, Mineralogy, Uses, Sustainability and Environmental Impact. Resources 2014, 3, 614-635. [CrossRef]

3. Silvestri, L.; Forcina, A.; Silvestri, C.; Traverso, M. Circularity Potential of Rare Earths for Sustainable Mobility: Recent Developments, Challenges and Future Prospects. J. Clean. Prod. 2021, 292, 126089. [CrossRef] 
4. Wang, Z.; Dai, S.; Zou, J.; French, D.; Graham, I.T. Rare Earth Elements and Yttrium in Coal Ash from the Luzhou Power Plant in Sichuan, Southwest China: Concentration, Characterization and Optimized Extraction. Int. J. Coal Geol. 2019, $203,1-14$. [CrossRef]

5. European Comission (EC). Critical Raw Materials Resilience: Charting a Path towards Greater Security and Sustainability; European Comission: Brussels, Belgium, 2020.

6. European Comission (EC). Tackling the Challenges in Commodity Markets and on Raw Materials; European Comission: Brussels, Belgium, 2011.

7. Bauer, D.; Diamond, D.; Li, J.; Sandalow, D.; Telleen, P.; Wanner, B.U.S. Department of Energy Critical Materials Strategy; U.S. Department of Energy: Washington, DC, USA, 2010. [CrossRef]

8. Alonso, E.; Sherman, A.M.; Wallington, T.J.; Everson, M.P.; Field, F.R.; Roth, R.; Kirchain, R.E. Evaluating Rare Earth Element Availability: A Case with Revolutionary Demand from Clean Technologies. Environ. Sci. Technol. 2012, 46, 3406-3414. [CrossRef] [PubMed]

9. Tang, M.; Zhou, C.; Zhang, N.; Pan, J.; Cao, S.; Hu, T.; Ji, W.; Wen, Z.; Nie, T. Extraction of Rare Earth Elements from Coal Fly Ash by Alkali Fusion-Acid Leaching: Mechanism Analysis. Int. J. Coal Prep. Util. 2019, 1-20. [CrossRef]

10. Massari, S.; Ruberti, M. Rare Earth Elements as Critical Raw Materials: Focus on International Markets and Future Strategies. Resour. Policy 2013, 38, 36-43. [CrossRef]

11. Dai, S.; Finkelman, R.B. Coal as a Promising Source of Critical Elements: Progress and Future Prospects. Int. J. Coal Geol. 2018, 186, 155-164. [CrossRef]

12. Franus, W.; Wiatros-Motyka, M.M.; Wdowin, M. Coal Fly Ash as a Resource for Rare Earth Elements. Environ. Sci. Pollut. Res. 2015, 22, 9464-9474. [CrossRef] [PubMed]

13. Hower, J.C.; Dai, S.; Seredin, V.V.; Zhao, L.; Kostova, I.J.; Silva, L.F.O.; Mardon, S.M.; Gurdal, G. A Note on the Occurrence of Yttrium and Rare Earth Elements in Coal Combustion Products. Coal Combust. Gasif. Prod. 2013, 5, 39-47. [CrossRef]

14. Hower, J.; Groppo, J.; Henke, K.; Hood, M.; Eble, C.; Honaker, R.; Zhang, W.; Qian, D. Notes on the Potential for the Concentration of Rare Earth Elements and Yttrium in Coal Combustion Fly Ash. Minerals 2015, 5, 356-366. [CrossRef]

15. Hower, J.C.; Groppo, J.G.; Henke, K.R.; Graham, U.M.; Hood, M.M.; Joshi, P.; Preda, D.V. Ponded and Landfilled Fly Ash as a Source of Rare Earth Elements from a Kentucky Power Plant. Coal Combust. Gasif. Prod. 2017, 9, 1-21. [CrossRef]

16. Blissett, R.S.; Smalley, N.; Rowson, N.A. An Investigation into Six Coal Fly Ashes from the United Kingdom and Poland to Evaluate Rare Earth Element Content. Fuel 2014, 119, 236-239. [CrossRef]

17. Dai, S.; Zhao, L.; Hower, J.C.; Johnston, M.N.; Song, W.; Wang, P.; Zhang, S. Petrology, Mineralogy, and Chemistry of SizeFractioned Fly Ash from the Jungar Power Plant, Inner Mongolia, China, with Emphasis on the Distribution of Rare Earth Elements. Energy Fuels 2014, 28, 1502-1514. [CrossRef]

18. Seredin, V.V.; Dai, S. Coal Deposits as Potential Alternative Sources for Lanthanides and Yttrium. Int. J. Coal Geol. 2012, 94, 67-93. [CrossRef]

19. Taggart, R.K.; Hower, J.C.; Dwyer, G.S.; Hsu-Kim, H. Trends in the Rare Earth Element Content of U.S.-Based Coal Combustion Fly Ashes. Environ. Sci. Technol. 2016, 50, 5919-5926. [CrossRef] [PubMed]

20. Hood, M.M.; Taggart, R.K.; Smith, R.C.; Hsu-Kim, H.; Henke, K.R.; Graham, U.; Groppo, J.G.; Unrine, J.M.; Hower, J.C. Rare Earth Element Distribution in Fly Ash Derived from the Fire Clay Coal, Kentucky. Coal Combust. Gasif. Prod. 2017, 9, 22-33. [CrossRef]

21. Rosita, W.; Bendiyasa, I.M.; Perdana, I.; Anggara, F. Sequential Particle-Size and Magnetic Separation for Enrichment of Rare-Earth Elements and Yttrium in Indonesia Coal Fly Ash. J. Environ. Chem. Eng. 2020, 8, 103575. [CrossRef]

22. Lin, R.; Howard, B.H.; Roth, E.A.; Bank, T.L.; Granite, E.J.; Soong, Y. Enrichment of Rare Earth Elements from Coal and Coal By-Products by Physical Separations. Fuel 2017, 200, 506-520. [CrossRef]

23. Liu, J.; Dai, S.; He, X.; Hower, J.C.; Sakulpitakphon, T. Size-Dependent Variations in Fly Ash Trace Element Chemistry: Examples from a Kentucky Power Plant and with Emphasis on Rare Earth Elements. Energy Fuels 2017, 31, 438-447. [CrossRef]

24. Lin, R.; Stuckman, M.; Howard, B.H.; Bank, T.L.; Roth, E.A.; Macala, M.K.; Lopano, C.; Soong, Y.; Granite, E.J. Application of Sequential Extraction and Hydrothermal Treatment for Characterization and Enrichment of Rare Earth Elements from Coal Fly Ash. Fuel 2018, 232, 124-133. [CrossRef]

25. Kose Mutlu, B.; Cantoni, B.; Turolla, A.; Antonelli, M.; Hsu-Kim, H.; Wiesner, M.R. Application of Nanofiltration for Rare Earth Elements Recovery from Coal Fly Ash Leachate: Performance and Cost Evaluation. Chem. Eng. J. 2018, 349, 309-317. [CrossRef]

26. Pan, J.; Zhou, C.; Liu, C.; Tang, M.; Cao, S.; Hu, T.; Ji, W.; Luo, Y.; Wen, M.; Zhang, N. Modes of Occurrence of Rare Earth Elements in Coal Fly Ash: A Case Study. Energy Fuels 2018, 32, 9738-9743. [CrossRef]

27. Stuckman, M.Y.; Lopano, C.L.; Granite, E.J. Distribution and Speciation of Rare Earth Elements in Coal Combustion By-Products via Synchrotron Microscopy and Spectroscopy. Int. J. Coal Geol. 2018, 195, 125-138. [CrossRef]

28. Wagner, N.J.; Matiane, A. Rare Earth Elements in Select Main Karoo Basin (South Africa) Coal and Coal Ash Samples. Int. J. Coal Geol. 2018, 196, 82-92. [CrossRef]

29. Thompson, R.L.; Bank, T.; Montross, S.; Roth, E.; Howard, B.; Verba, C.; Granite, E. Analysis of Rare Earth Elements in Coal Fly Ash Using Laser Ablation Inductively Coupled Plasma Mass Spectrometry and Scanning Electron Microscopy. Spectrochim. Acta Part B At. Spectrosc. 2018, 143, 1-11. [CrossRef]

30. Park, S.; Kim, M.; Lim, Y.; Yu, J.; Chen, S.; Woo, S.W.; Yoon, S.; Bae, S.; Kim, H.S. Characterization of Rare Earth Elements Present in Coal Ash by Sequential Extraction. J. Hazard. Mater. 2021, 402, 123760. [CrossRef] [PubMed] 
31. Ketris, M.P.; Yudovich, Y.E. Estimations of Clarkes for Carbonaceous Biolithes: World Averages for Trace Element Contents in Black Shales and Coals. Int. J. Coal Geol. 2009, 78, 135-148. [CrossRef]

32. Rudnick, R.L.; Gao, S. Composition of the Continental Crust. In Treatise on Geochemistry; Holland, H.D., Turekian, K.K., Eds.; Elsevier: Amsterdam, The Netherlands, 2014; pp. 1-51. ISBN 9780080983004.

33. Seredin, V.V. Rare Earth Element-Bearing Coals from the Russian Far East Deposits. Int. J. Coal Geol. 1996, 30, 101-129. [CrossRef]

34. Hower, J.C.; Ruppert, L.F.; Eble, C.F. Lanthanide, Yttrium, and Zirconium Anomalies in the Fire Clay Coal Bed, Eastern Kentucky. Int. J. Coal Geol. 1999, 39, 141-153. [CrossRef]

35. Hower, J.C.; Eble, C.F.; Dai, S.; Belkin, H.E. Distribution of Rare Earth Elements in Eastern Kentucky Coals: Indicators of Multiple Modes of Enrichment? Int. J. Coal Geol. 2016, 160-161, 73-81. [CrossRef]

36. Dai, S.; Liu, J.; Ward, C.R.; Hower, J.C.; French, D.; Jia, S.; Hood, M.M.; Garrison, T.M. Mineralogical and Geochemical Compositions of Late Permian Coals and Host Rocks from the Guxu Coalfield, Sichuan Province, China, with Emphasis on Enrichment of Rare Metals. Int. J. Coal Geol. 2016, 166, 71-95. [CrossRef]

37. International Energy Agency (IEA). Coal 2020; IEA Publications: Paris, France, 2020.

38. Clarke, L.B.; Sloss, L.L. Trace Elements: Emissions from Coal Combustion and Gasification; IEA Coal Research: London, UK, 1992; ISBN 9290292040

39. Meij, R. The Distribution of Trace Elements During the Combustion of Coal. In Environmental Aspects of Trace Elements in Coal. Energy E Environment; Swaine, D.J., Goodarzi, F., Eds.; Springer: Dordrecht, The Netherlands, 1995; Volume 2, pp. 111-127. ISBN 978-90-481-4606-2.

40. Ratafia-Brown, J.A. Overview of Trace Element Partitioning in Flames and Furnaces of Utility Coal-Fired Boilers. Fuel Process. Technol. 1994, 39, 139-157. [CrossRef]

41. Fu, B.; Hower, J.C.; Zhang, W.; Luo, G.; Hu, H.; Yao, H. A Review of Rare Earth Elements and Yttrium in Coal Ash: Content, Modes of Occurrences, Combustion Behavior, and Extraction Methods. Prog. Energy Combust. Sci. 2022, 88, 100954. [CrossRef]

42. Dai, S.; Zhao, L.; Peng, S.; Chou, C.-L.; Wang, X.; Zhang, Y.; Li, D.; Sun, Y. Abundances and Distribution of Minerals and Elements in High-Alumina Coal Fly Ash from the Jungar Power Plant, Inner Mongolia, China. Int. J. Coal Geol. 2010, 81, 320-332. [CrossRef]

43. Ma, Z.; Shan, X.; Cheng, F. Distribution Characteristics of Valuable Elements, Al, Li, and Ga, and Rare Earth Elements in Feed Coal, Fly Ash, and Bottom Ash from a 300 MW Circulating Fluidized Bed Boiler. ACS Omega 2019, 4, 6854-6863. [CrossRef] [PubMed]

44. Wei, Q.; Song, W. Mineralogical and Chemical Characteristics of Coal Ashes from Two High-Sulfur Coal-Fired Power Plants in Wuhai, Inner Mongolia, China. Minerals 2020, 10, 323. [CrossRef]

45. Lanzerstorfer, C. Fly Ash from Coal Combustion: Dependence of the Concentration of Various Elements on the Particle Size. Fuel 2018, 228, 263-271. [CrossRef]

46. Hower, J.C.; Hood, M.M.; Taggart, R.K.; Hsu-Kim, H. Chemistry and Petrology of Paired Feed Coal and Combustion Ash from Anthracite-Burning Stoker Boilers. Fuel 2017, 199, 438-446. [CrossRef]

47. Mardon, S.M.; Hower, J.C. Impact of Coal Properties on Coal Combustion By-Product Quality: Examples from a Kentucky Power Plant. Int. J. Coal Geol. 2004, 59, 153-169. [CrossRef]

48. Hower, J.C.; Fu, B.; Dai, S. Geochemical Partitioning from Pulverized Coal to Fly Ash and Bottom Ash. Fuel 2020, 279 , 118542. [CrossRef]

49. Campbell, J.A.; Laul, J.C.; Nielson, K.K.; Smith, R.D. Separation and Chemical Characterization of Finely-Sized Fly-Ash Particles. Anal. Chem. 1978, 50, 1032-1040. [CrossRef]

50. Seredin, V.V. A New Method for Primary Evaluation of the Outlook for Rare Earth Element Ores. Geol. Ore Depos. 2010, 52, 428-433. [CrossRef]

51. Dai, S.; Xie, P.; Jia, S.; Ward, C.R.; Hower, J.C.; Yan, X.; French, D. Enrichment of U-Re-V-Cr-Se and Rare Earth Elements in the Late Permian Coals of the Moxinpo Coalfield, Chongqing, China: Genetic Implications from Geochemical and Mineralogical Data. Ore Geol. Rev. 2017, 80, 1-17. [CrossRef]

52. McLellan, B.; Corder, G.; Ali, S. Sustainability of Rare Earths-An Overview of the State of Knowledge. Minerals 2013, 3, 304-317. [CrossRef]

53. Harris, D.; Feuerborn, J.; Heidrich, C.; Feuerborn Kurzfassung, J. Global Aspects on Coal Combustion Products. In Proceedings of the World of Coal Ash (WOCA), St. Louis, MO, USA, 13 May 2019; Volume 10.

54. ASTM D7582. Standard Test Methods for Proximate Analysis of Coal and Coke by Macro Thermogravimetric Analysis. American Society for Testing and Materials: West Conshohocken, PA, USA, 2015; p. 9.

55. ASTM D5373. Standard Test Methods for Determination of Carbon, Hydrogen and Nitrogen in Analysis Samples of Coal and Carbon in Analysis Samples of Coal and Coke. American Society for Testing and Materials: West Conshohocken, PA, USA, 2016; p. 11.

56. ASTM D4239. Standard Test Method for Sulfur in the Analysis Sample of Coal and Coke Using High-Temperature Tube Furnace Combustion. American Society for Testing and Materials: West Conshohocken, PA, USA, 2018; p. 8.

57. ISO 11722. Solid Mineral Fuels-Hard Coal-Determination of Moisture in the General Analysis Test Sample by Drying in Nitrogen. International Organization for Standardization: Geneva, Switzerland, 2013; p. 5.

58. ISO 1171. Solid Mineral Fuels—Determination of Ash. International Organization for Standardization: Geneva, Switzerland, 2010; p. 4. 
59. ISO 562. Hard Coal and Coke-Determination of Volatile Matter. International Organization for Standardization: Geneva, Switzerland, 2010; p. 8.

60. ISO 1170. Coal and Coke-Calculation of Analyses to Different Bases. International Organization for Standardization: Geneva, Switzerland, 2013; p. 7.

61. ISO 17246. Coal-Proximate Analysis. International Organization for Standardization: Geneva, Switzerland, $2005 ;$ p. 3.

62. Godoy, M.L.D.P.; Godoy, J.M.; Roldao, L.A. Determination of Trace Elements in Coal and Coal Ash Samples by ICP-MS. At. Spectrosc. 2001, 22, 235-243.

63. Whitty-Léveillé, L.; Drouin, E.; Constantin, M.; Bazin, C.; Larivière, D. Scandium Analysis in Silicon-Containing Minerals by Inductively Coupled Plasma Tandem Mass Spectrometry. Spectrochim. Acta Part B At. Spectrosc. 2016, 118, 112-118. [CrossRef]

64. Taylor, J.C. Computer Programs for Standardless Quantitative Analysis of Minerals Using the Full Powder Diffraction Profile. Powder Diffr. 1991, 6, 2-9. [CrossRef]

65. ISO 7404-2. Methods for the Petrographic Analysis of Coals-Part 2: Methods of Preparing Coal Samples. International Organization for Standardization: Geneva, Switzerland, 2009; p. 12.

66. ISO 7404-3. Methods for the Petrographic Analysis of Coals-Part 3: Method of Determining Maceral Group Composition. International Organization for Standardization: Geneva, Switzerland, 2009; p. 7.

67. ICCP (International Committee for Coal and Organic Petrology). The New Vitrinite Classification (ICCP System 1994). Fuel 1998, 77, 349-358. [CrossRef]

68. ICCP (International Committee for Coal and Organic Petrology). The New Inertinite Classification (ICCP System 1994). Fuel 2001, 80, 459-471. [CrossRef]

69. Pickel, W.; Kus, J.; Flores, D.; Kalaitzidis, S.; Christanis, K.; Cardott, B.J.; Misz-Kennan, M.; Rodrigues, S.; Hentschel, A.; Hamor-Vido, M.; et al. Classification of Liptinite-ICCP System 1994. Int. J. Coal Geol. 2017, 169, 40-61. [CrossRef]

70. Sýkorová, I.; Pickel, W.; Christanis, K.; Wolf, M.; Taylor, G.H.; Flores, D. Classification of Huminite-ICCP System 1994. Int. J. Coal Geol. 2005, 62, 85-106. [CrossRef]

71. Hower, J.C. Petrographic Examination of Coal-Combustion Fly Ash. Int. J. Coal Geol. 2012, 92, 90-97. [CrossRef]

72. Valentim, B.; Abagiu, A.T.; Anghelescu, L.; Flores, D.; French, D.; Gonçalves, P.; Guedes, A.; Popescu, L.G.; Predeanu, G.; Ribeiro, J.; et al. Assessment of Bottom Ash Landfilled at Ceplea Valley (Romania) as a Source of Rare Earth Elements. Int. J. Coal Geol. 2019, 201, 109-126. [CrossRef]

73. Valentim, B.; Hower, J.C.; Flores, D.; Guedes, A. Notes on the Efficacy of Wet versus Dry Screening of Fly Ash. Min. Metall. Explor. 2008, 25, 143-148. [CrossRef]

74. Hower, J.C.; Thomas, G.A.; Palmer, J. Impact of the Conversion to Low-NOx Combustion on Ash Characteristics in a Utility Boiler Burning Western US Coal. Fuel Processing Technol. 1999, 61, 175-195. [CrossRef]

75. Dai, S.; Graham, I.T.; Ward, C.R. A Review of Anomalous Rare Earth Elements and Yttrium in Coal. Int. J. Coal Geol. 2016, 159, 82-95. [CrossRef]

76. Bau, M.; Dulski, P. Distribution of Yttrium and Rare-Earth Elements in the Penge and Kuruman Iron-Formations, Transvaal Supergroup, South Africa. Precambrian Res. 1996, 79, 37-55. [CrossRef]

77. ISO 11760. Classification of Coals. International Organization for Standardization: Geneva, Switzerland, 2005 ; p. 9.

78. Chou, C.-L. Sulfur in Coals: A Review of Geochemistry and Origins. Int. J. Coal Geol. 2012, 100, 1-13. [CrossRef]

79. Finkelman, R.B.; Palmer, C.A.; Wang, P. Quantification of the Modes of Occurrence of 42 Elements in Coal. Int. J. Coal Geol. 2018, 185, 138-160. [CrossRef]

80. van Krevelen, D.W. Coal: Typology-Physics-Chemistry-Constitution; Elsevier Science: Amsterdam, The Netherlands, 1993 ; p. 979.

81. ASTM D388. Standard Classification of Coals by Rank. American Society for Testing and Materials: West Conshohocken, PA, USA, 1999; p. 8.

82. Speight, J.G. Handbook of Coal Analysis, 2nd ed.; Vitha, M.F., Ed.; John Wiley \& Sons Inc.: Hoboken, NJ, USA, 2015; ISBN 9781119037699.

83. Valentim, B.; Lemos de Sousa, M.J.; Abelha, P.; Boavida, D.; Gulyurtlu, I. The Identification of Unusual Microscopic Features in Coal and Their Derived Chars: Influence on Coal Fluidized Bed Combustion. Int. J. Coal Geol. 2006, 67, 202-211. [CrossRef]

84. Valentim, B.; Hower, J.C.; Guedes, A.; Flores, D. Scanning Electron Microscopy And Energy-Dispersive X-Ray Spectroscopy Of Low-Sulfur Coal Fly Ash. Int. J. Energy Clean Environ. 2009, 10, 147-166. [CrossRef]

85. Laskowski, J.S. Coal Flotation and Fine Coal Utilization, 1st ed.; Elsevier Science: Amsterdam, The Netherlands, 2001; Volume 14, ISBN 9780080529240.

86. Yuan, Y.; Tang, S.; Zhang, S. Geochemical and Mineralogical Characteristics of the Middle Jurassic Coals from the Tongjialiang Mine in the Northern Datong Coalfield, Shanxi Province, China. Minerals 2019, 9, 184. [CrossRef]

87. Ward, C.R. Analysis, Origin and Significance of Mineral Matter in Coal: An Updated Review. Int. J. Coal Geol. 2016, 165, 1-27. [CrossRef]

88. Oliveira, M.L.S.; Ward, C.R.; French, D.; Hower, J.C.; Querol, X.; Silva, L.F.O. Mineralogy and Leaching Characteristics of Beneficiated Coal Products from Santa Catarina, Brazil. Int. J. Coal Geol. 2012, 94, 314-325. [CrossRef]

89. Folk, R.L.; Ward, W.C. Brazos River Bar [Texas]; a Study in the Significance of Grain Size Parameters. J. Sediment. Res. 1957, 27, 3-26. [CrossRef] 
90. Ahn, Y.C.; Lee, J.K. Physical, Chemical, and Electrical Analysis of Aerosol Particles Generated from Industrial Plants. J. Aerosol Sci. 2006, 37, 187-202. [CrossRef]

91. Suárez-Ruiz, I.; Hower, J.C.; Thomas, G.A. Hg and Se Capture and Fly Ash Carbons from Combustion of Complex Pulverized Feed Blends Mainly of Anthracitic Coal Rank in Spanish Power Plants. Energy Fuels 2007, 21, 59-70. [CrossRef]

92. Senneca, O. Burning and Physico-Chemical Characteristics of Carbon in Ash from a Coal Fired Power Plant. Fuel 2008, 87, 1207-1216. [CrossRef]

93. Vassilev, S.V.; Vassileva, C.G. A New Approach for the Classification of Coal Fly Ashes Based on Their Origin, Composition, Properties, and Behaviour. Fuel 2007, 86, 1490-1512. [CrossRef]

94. ASTM C618. Coal Fly Ash and Raw or Calcined Natural Pozzolan for Use in Concrete. American Society for Testing and Materials: West Conshohocken, PA, USA, 2005; p. 3.

95. Matjie, R.H.; van Alphen, C.; Pistorius, P.C. Mineralogical Characterisation of Secunda Gasifier Feedstock and Coarse Ash. Miner. Eng. 2006, 19, 256-261. [CrossRef]

96. Kolker, A.; Scott, C.; Hower, J.C.; Vazquez, J.A.; Lopano, C.L.; Dai, S. Distribution of Rare Earth Elements in Coal Combustion Fly Ash, Determined by SHRIMP-RG Ion Microprobe. Int. J. Coal Geol. 2017, 184, 1-10. [CrossRef]

97. Valentim, B.; Białecka, B.; Gonçalves, P.; Guedes, A.; Guimarães, R.; Cruceru, M.; Całus-Moszko, J.; Popescu, L.; Predeanu, G.; Santos, A. Undifferentiated Inorganics in Coal Fly Ash and Bottom Ash: Calcispheres, Magnesiacalcispheres, and Magnesiaspheres. Minerals 2018, 8, 140. [CrossRef]

98. Hulett, L.D.; Weinberger, A.J. Some Etching Studies of the Microstructure and Composition of Large Aluminosilicate Particles in Fly Ash from Coal-Burning Power Plants. Environ. Sci. Technol. 1980, 14, 965-970. [CrossRef] [PubMed]

99. Henry, J.; Towler, M.; Stanton, K.; Querol, X.; Moreno, N. Characterisation of the Glass Fraction of a Selection of European Coal Fly Ashes. J. Chem. Technol. Biotechnol. 2004, 79, 540-546. [CrossRef]

100. Valentim, B.; Guedes, A.; Flores, D.; Ward, C.R.; Hower, J.C. Variations in Fly Ash Composition with Sampling Location: Case Study from a Portuguese Power Plant. Coal Combust. Gasif. Prod. 2009, 1, 14-24. [CrossRef]

101. Lauf, R.J.; Harris, L.A.; Rawlston, S.S. Pyrite Framboids as the Source of Magnetite Spheres in Fly Ash. Environ. Sci. Technol. 1982, 16, 218-220. [CrossRef]

102. Sokol, E.V.; Kalugin, V.M.; Nigmatulina, E.N.; Volkova, N.I.; Frenkel, A.E.; Maksimova, N.V. Ferrospheres from Fly Ashes of Chelyabinsk Coals: Chemical Composition, Morphology and Formation Conditions. Fuel 2002, 81, 867-876. [CrossRef]

103. Finkelman, R.B. Trace and Minor Elements in Coal. In Organic Geochemistry; Topics in Geobiology; Engel, M.H., Macko, S.A., Eds.; Springer: Boston, MA, USA, 1993; Volume 11, pp. 593-607.

104. Dai, S.; Tian, L.; Chou, C.-L.; Zhou, Y.; Zhang, M.; Zhao, L.; Wang, J.; Yang, Z.; Cao, H.; Ren, D. Mineralogical and Compositional Characteristics of Late Permian Coals from an Area of High Lung Cancer Rate in Xuan Wei, Yunnan, China: Occurrence and Origin of Quartz and Chamosite. Int. J. Coal Geol. 2008, 76, 318-327. [CrossRef]

105. Dai, S.; Seredin, V.V.; Ward, C.R.; Hower, J.C.; Xing, Y.; Zhang, W.; Song, W.; Wang, P. Enrichment of U-Se-Mo-Re-V in Coals Preserved within Marine Carbonate Successions: Geochemical and Mineralogical Data from the Late Permian Guiding Coalfield, Guizhou, China. Miner. Depos. 2015, 50, 159-186. [CrossRef]

106. Clarke, L.B. The Fate of Trace Elements during Coal Combustion and Gasification: An Overview. Fuel 1993, 72, 731-736. [CrossRef]

107. Liu, P.; Huang, R.; Tang, Y. Comprehensive Understandings of Rare Earth Element (REE) Speciation in Coal Fly Ashes and Implication for REE Extractability. Environ. Sci. Technol. 2019, 53, 5369-5377. [CrossRef] [PubMed]

108. Eskanazy, G.; Finkelman, R.B.; Chattarjee, S. Some Considerations Concerning the Use of Correlation Coefficients and Cluster Analysis in Interpreting Coal Geochemistry Data. Int. J. Coal Geol. 2010, 83, 491-493. [CrossRef]

109. Gürdal, G. Abundances and Modes of Occurrence of Trace Elements in the Çan Coals (Miocene), Çanakkale-Turkey. Int. J. Coal Geol. 2011, 87, 157-173. [CrossRef]

110. Zhao, L.; Ward, C.; French, D.; Graham, I. Major and Trace Element Geochemistry of Coals and Intra-Seam Claystones from the Songzao Coalfield, SW China. Minerals 2015, 5, 870-893. [CrossRef]

111. Hower, J.C.; Qian, D.; Briot, N.J.; Henke, K.R.; Hood, M.M.; Taggart, R.K.; Hsu-Kim, H. Rare Earth Element Associations in the Kentucky State University Stoker Ash. Int. J. Coal Geol. 2018, 189, 75-82. [CrossRef]

112. Rollinson, H.R. Using Geochemical Data: Evaluation, Presentation, Interpretation; Routledge: Abingdon, UK, 2014. [CrossRef]

113. Montross, S.N.; Verba, C.A.; Chan, H.L.; Lopano, C. Advanced Characterization of Rare Earth Element Minerals in Coal Utilization Byproducts Using Multimodal Image Analysis. Int. J. Coal Geol. 2018, 195, 362-372. [CrossRef]

114. Hower, J.C.; Groppo, J.G. Rare Earth-Bearing Particles in Fly Ash Carbons: Examples from the Combustion of Eastern Kentucky Coals. Energy Geosci. 2021, 2, 90-98. [CrossRef]

115. Hower, J.C.; Qian, D.; Briot, N.J.; Santillan-Jimenez, E.; Hood, M.M.; Taggart, R.K.; Hsu-Kim, H. Nano-Scale Rare Earth Distribution in Fly Ash Derived from the Combustion of the Fire Clay Coal, Kentucky. Minerals 2019, 9, 206. [CrossRef]

116. Izquierdo, M.; Querol, X. Leaching Behaviour of Elements from Coal Combustion Fly Ash: An Overview. Int. J. Coal Geol. 2012, 94, 54-66. [CrossRef]

117. Bartoňová, L.; Serenčíšová, J.; Čech, B. Yttrium Partitioning and Associations in Coal-Combustion Ashes Prior to and after Their Leaching in HCl. Fuel Processing Technol. 2018, 173, 205-215. [CrossRef]

118. Pan, J.; Zhou, C.; Tang, M.; Cao, S.; Liu, C.; Zhang, N.; Wen, M.; Luo, Y.; Hu, T.; Ji, W. Study on the Modes of Occurrence of Rare Earth Elements in Coal Fly Ash by Statistics and a Sequential Chemical Extraction Procedure. Fuel 2019, 237, 555-565. [CrossRef] 
119. Taggart, R.K.; Rivera, N.A.; Levard, C.; Ambrosi, J.-P.; Borschneck, D.; Hower, J.C.; Hsu-Kim, H. Differences in Bulk and Microscale Yttrium Speciation in Coal Combustion Fly Ash. Environ. Sci. Processes Impacts 2018, 20, 1390-1403. [CrossRef] [PubMed]

120. Finch, R.J. Structure and Chemistry of Zircon and Zircon-Group Minerals. Rev. Mineral. Geochem. 2003, 53, 1-25. [CrossRef]

121. Watson, E.B.; Harrison, T.M. Zircon Saturation Revisited: Temperature and Composition Effects in a Variety of Crustal Magma Types. Earth Planet. Sci. Lett. 1983, 64, 295-304. [CrossRef]

122. Nugroho, N.D.; Rosita, W.; Perdana, I.; Bendiyasa, I.M.; Mufakhir, F.R.; Astuti, W. Iron Bearing Oxide Minerals Separation from Rare Earth Elements (REE) Rich Coal Fly Ash. IOP Conf. Ser. Mater. Sci. Eng. 2019, 478, 012026. [CrossRef]

123. Dapkunas, S.J.; Jillavenkatesa, A. NIST Recommended Practice Guide; National Institute of Standards and Technology: Gaithersburg, MD, USA, 2001.

124. Merkus, H.G. Particle Size, Size Distributions and Shape. Part. Size Meas. 2009, 17, 13-42. [CrossRef]

125. Hrnčířová, M.; Pospíšil, J.; Michalšpiláček, M.M. Size Analysis of Solid Particles Using Laser Diffraction and Sieve Analysis. Eng. Mech. 2013, 20, 309-318.

126. Wills, B.A.; Napier-Munn, T. Introduction. In Wills' Mineral Processing Technology; Butterworth-Heinemann: Oxford, UK, 2005; pp. 1-29. ISBN 978-0-08-097053-0.

127. Lanzerstorfer, C. Pre-Processing of Coal Combustion Fly Ash by Classification for Enrichment of Rare Earth Elements. Energy Rep. 2018, 4, 660-663. [CrossRef]

128. Hower, J.C.; Groppo, J.G.; Jewell, R.B.; Wiseman, J.D.; Duvallet, T.Y.; Oberlink, A.E.; Hopps, S.D.; Morgan, T.D.; Henke, K.R.; Joshi, P.; et al. Distribution of Rare Earth Elements in the Pilot-Scale Processing of Fly Ashes Derived from Eastern Kentucky Coals: Comparisons of the Feed and Processed Ashes. Fuel 2021, 295, 120562. [CrossRef] 